\title{
How do olivines record magmatic events? Insights from major and trace element zoning
}

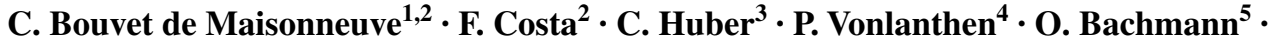 \\ M. A. Dungan ${ }^{1,6}$
}

Received: 3 September 2015 / Accepted: 25 April 2016/ Published online: 27 May 2016

(C) The Author(s) 2016. This article is published with open access at Springerlink.com

\begin{abstract}
Reconciling the diverse records of magmatic events preserved by multiple crystals and minerals in the same sample is often challenging. In the case of basalticandesites from Volcán Llaima (Chile), Mg zoning in olivine is always simpler than $\mathrm{Ca}$ zoning in plagioclase. A model that explains a number of chemical patterns is that Llaima magmas stall in the upper crust, where they undergo decompression crystallization and form crystal-mush bodies. Frequent magma inputs from deeper reservoirs provide the potential for remobilization and eruption. The records of multiple recharge events in Llaima plagioclase versus an apparent maximum of one such event in coexisting olivine are addressed by using trace element zoning in olivine
\end{abstract}

Communicated by Timothy L. Grove.

Electronic supplementary material The online version of this article (doi:10.1007/s00410-016-1264-6) contains supplementary material, which is available to authorized users.

C. Bouvet de Maisonneuve

carolinebouvet@ntu.edu.sg

1 Department of Earth and Environmental Sciences, University of Geneva, 13 rue des Maraichers, 1205 Geneva, Switzerland

2 Present Address: Earth Observatory of Singapore - Asian School of the Environment, Nanyang Technological University, Singapore 639798, Singapore

3 School of Earth and Atmospheric Sciences, Georgia Institute of Technology, Atlanta, GA 30332, USA

4 Institute of Earth Sciences, University of Lausanne, 1015 Lausanne, Switzerland

5 Department of Earth Sciences, Institute of Geochemistry and Petrology, ETHZ, 8092 Zurich, Switzerland

6 Present Address: Department of Geological Sciences, University of Oregon, Eugene, OR 97402, USA phenocrysts. We have integrated elements that (1) respond to changes in magma composition due to recharge or mixing $(\mathrm{Mg}, \mathrm{Fe}, \mathrm{Ni}, \mathrm{Mn}, \pm \mathrm{Ca}$ ), with (2) elements that are incorporated during rapid, disequilibrium crystal growth (P, Ti, Sc, V, Al). A more complex history is obtained when these elements are evaluated considering their partition coefficients, diffusivities, and crystal growth rates. The olivine archive can then be reconciled with the plagioclase archive of magma reservoir processes. Olivine (and plagioclase) phenocrysts may experience up to three or more recharge events between nucleation and eruption. Diffusion modeling of major and trace element zoning in two dimensions using a new lattice Boltzmann model suggests that recharge events occur on the order of months to a couple of years prior to eruption, whereas crystal residence times are more likely to be on the order of a few years to decades.

Keywords Crystal archives · Olivine zoning · Trace elements $\cdot$ Magma recharge $\cdot$ Timescales

\section{Introduction}

Mineral textures and chemical zoning have long been recognized as archives of subvolcanic magmatic processes (Larsen et al. 1938; Tomkeieff 1939) and are now routinely used to address open-system processes such as magma recharge or assimilation in magma reservoirs (e.g., Blundy and Cashman 2008; Streck 2008). If the evolution of erupted magmas were a continuous single-stage, closedsystem process that occurred under a simple path of pressure, temperature, and composition, minerals would be homogeneous or display simple zoning profiles, without reversals or discontinuities, and they could be used with minimal ambiguity to quantify parameters such as pressure, 
temperature, oxygen fugacity, melt composition, process rates, residence times, and/or water content. This scenario is extremely rare, particularly in the continental arc setting, where magma evolution is typically polybaric, and where there is a high probability of mixing with resident magmas and/or interactions with wall rocks (e.g., Costa et al. 2013). Magmatic processes commonly lead to hybrid magmas that carry a history of (1) crystallization over ranges of pressure, temperature, and volatile contents, (2) magma mixing and blended crystal cargoes, (3) assimilation of host rocks and the addition of xenocrysts and xenoliths, and (4) entrainment of crystals (antecrysts) from a long-lived mush layer.

Zoning patterns in minerals offer opportunities to address unanswered questions raised by glass and wholerock chemistry on the basis of the ability of minerals to record processes and events as a function of time and magma composition, and their capacity to retain such records where the timescales of processes and the diffusion rates of key elements in these minerals are amenable (e.g., Costa et al. 2008). This article focuses on utilizing olivine for such purposes despite the rapid rate at which diffusive equilibration may eliminate the record of magmatic events for fast-diffusing elements (i.e., $\mathrm{Fe}-\mathrm{Mg}-\mathrm{Ca}-\mathrm{Ni}-\mathrm{Mn}$; Chakraborty 2010).

Minerals such as plagioclase may record and faithfully preserve these complexities on short length scales over long timescales. Other minerals typically undergo progressive re-equilibration with evolving magmas, at least for certain fast-diffusing elements (e.g., Costa et al. 2008; Costa and Morgan 2010 and references therein), thereby restricting their application to relatively recent, open-system events. Coupled substitutions in pyroxenes and amphiboles may preserve the records of complex magmatic histories better than olivine usually does. It is frequently observed that plagioclase documents many events through the combination of resorption surfaces and associated, nominally concentric zoning in An content $(100 \times \mathrm{Ca} /[\mathrm{Ca}+\mathrm{Na}+\mathrm{K}]$ in $\mathrm{mol} \%$ ), including oscillatory zoning. At the other end of the spectrum, olivine crystals in the same thin section generally manifest much simpler zoning patterns, which may include broad, non-zoned cores. The first-order explanation for "simplified" records in olivine is that major and minor bivalent elements that are easily accessible with the electron microprobe diffuse rapidly relative to the timescales of recurring eruptions at active volcanoes (years to centuries; see review by Chakraborty 2010). Compositional gradients in olivine recorded by $\mathrm{Mg}, \mathrm{Fe}, \mathrm{Ni}$, and $\mathrm{Mn}$ may be extensively diffused in a few years and eliminated in a few decades, depending on their size, the temperature, and the boundary conditions. Coupled Anorthite-Albite zoning in plagioclase is far more resistant to resetting due to $\mathrm{Si}$ and $\mathrm{Al}$ that are tightly bound in tetrahedral coordination (Grove et al. 1984). Here, we address how plagioclase and olivine mineral records broadly compare in basaltic-andesites from Volcán Llaima $\left(38.7^{\circ} \mathrm{S}\right.$, Andean Southern Volcanic Zone).

Llaima is a hyperactive volcano that has been characterized by Strombolian-style explosive activity followed by lava extrusion for the last few 1000 years. It has been studied in detail in order to document and interpret linkages among magma genesis, magma storage and differentiation, and eruption processes at a typical Strombolian-type volcano (Naranjo and Moreno 2005; Reubi, et al. 2011; Bouvet de Maisonneuve et al. 2012, 2013; Ruth 2014; Schindlbeck et al. 2014). This high eruption frequency of approximately one eruption every 5-6 years (Dzierma and Wehrmann 2010) requires a higher net volume and frequency of magma recharge events, given intrusive/extrusive volume ratios $\gg 1$, as are estimated from passive degassing at open-vent volcanoes (Kazahaya et al. 1994; Shinohara 2008). Llaima's elevated rates of eruption and recharge make it an ideal edifice for investigating detailed records of major and trace element variations in phenocrysts and antecrysts.

A model for Late Holocene Llaima activity (Fig. 1; Bouvet de Maisonneuve et al. 2012) is that evolved basaltic recharge magmas stall at shallow subedifice depths $(\leq 4 \mathrm{~km})$, where they undergo decompression crystallization (Blundy and Cashman 2005) to large extents and form resident mush bodies. Frequent magma inputs from deeper reservoirs maintain non-erupted mush in a viable state for remobilization and subsequent eruption. Magmas are stored in a plexus of partly interconnected, upper-crustal dikes and sills. This scenario implies that some magma batches are most likely isolated from others during periods of lowfrequency recharge. Under these conditions, different parts of the conduit/reservoir system would experience variable frequencies and volumes of recharge and would reach different extents of differentiation due to crystal fractionation. This model explains a number of chemical and textural features recorded by melt inclusions, and by olivine and plagioclase phenocrysts (Bouvet de Maisonneuve et al. 2012, 2013). However, it has lacked a quantitative explanation for why plagioclase crystals often record a series of recharge events and coexisting olivine grains appear to record only one according to $\mathrm{Fe}-\mathrm{Mg}-\mathrm{Ni}-\mathrm{Mn}$ variations. Although the An content of plagioclase is very dependent on the water content in the melt, unlike the $\mathrm{Fe}-\mathrm{Mg}$ content of olivine, the large (>10 mol\%) changes in An content ought to reflect large changes in magma composition and temperature that should also be recorded by $\mathrm{Fe}-\mathrm{Mg}$ in olivine. We suggest that the resolution of this seeming paradox at Llaima may have general applicability to arc magmas that evolve in open systems.

We have obtained major and trace element zoning patterns of olivine phenocrysts by electron microprobe 


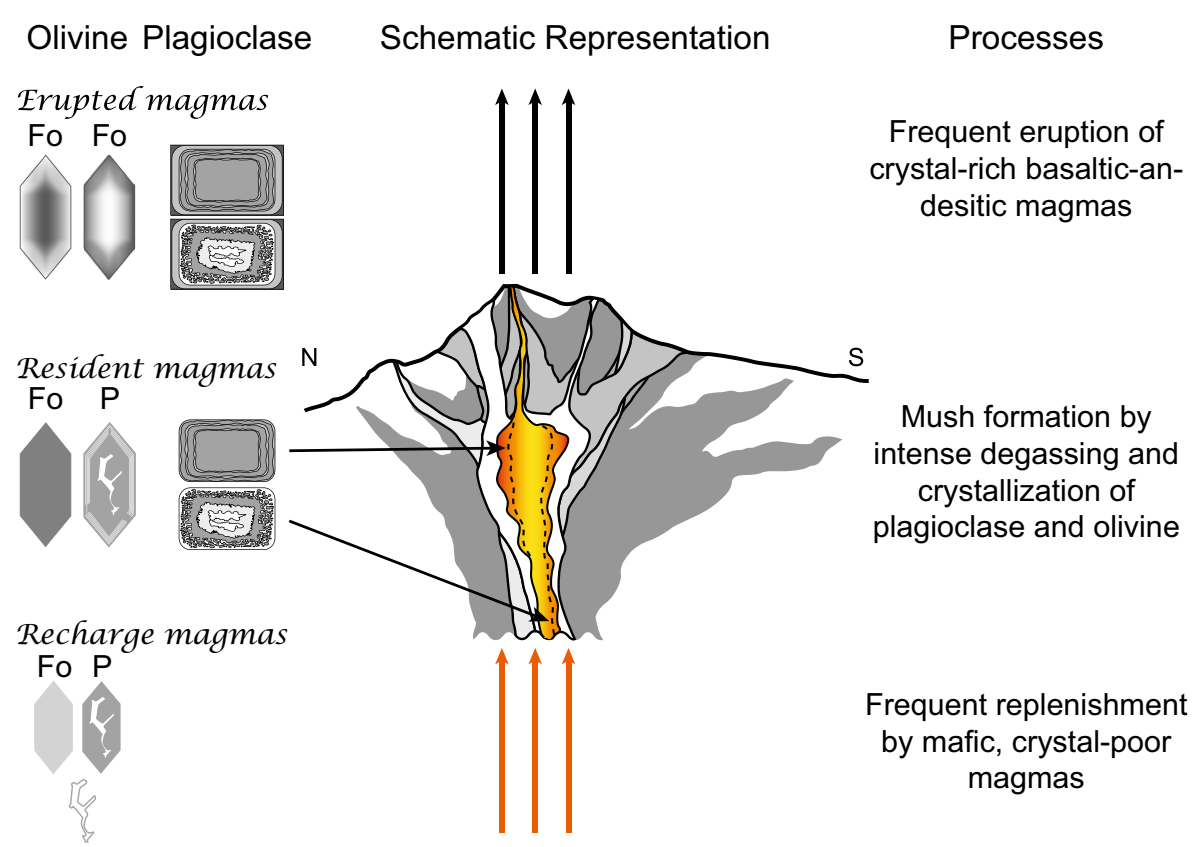

Fig. 1 Schematic representation of the dominant magmatic processes operating in the shallow reservoirs of Volcán Llaima. A balance is reached between the frequency of recharge events, the time allowed for crystallization, and the frequency of eruptions, allowing for the eruption of compositionally homogeneous but texturally complex samples. Textural complexity in erupted magmas is represented by the uppermost plagioclase and olivine crystals that have varied and complex zoning patterns. Plagioclase textures are affected by variable

(profiles and maps) and laser ablation ICP-MS (profiles), and investigated them within a theoretical framework of crystal growth and element diffusion. We show that combining elements recording changes in magma composition (i.e., magma recharge or mixing: $\mathrm{Fe}, \mathrm{Mg}, \pm \mathrm{Ca}, \mathrm{Mn}$, $\mathrm{Ni}$ ) with elements that are sensitive to disequilibrium crystallization (i.e., rapid growth: $\mathrm{P}, \pm \mathrm{Al}, \mathrm{Ti}, \mathrm{Sc}, \mathrm{V})$, while bearing in mind their respective diffusivities, enables the recovery of a much more complex history than could be inferred from Fo zoning alone (i.e., $100 \times \mathrm{Mg} /$ $[\mathrm{Mg}+\mathrm{Fe}]$ in $\mathrm{mol} \%)$. It is only after such a detailed analysis that the olivine archive could be reconciled with the plagioclase archive of magma reservoir processes: Both minerals record multiple magma recharge events and have therefore experienced similar magmatic histories. A new two-dimensional diffusion model using the lattice Boltzmann method was developed and used to estimate the relative timing of magmatic events recorded by the olivine phenocrysts. Magma recharge events are recorded by Fo zoning at the rim and occur on the order of a few months to a couple of years prior to eruption. Ti zoning in the core suggests that a couple of crystals formed on the order of at least a few years to decades prior to eruption. Individual phenocrysts may experience up to three degrees of interaction with recharge magma between the base and the top of the reservoirs. The presence of multiple reservoirs is recorded by variable olivine core compositions. Olivine zoning in elements with very different geochemical properties allows the identification of crystals contributed by the recharge magma (normally zoned in Fo, relatively simple $\mathrm{P}$ zoning) or by the resident magma in the shallow reservoirs (reversely zoned in Fo, more complex $\mathrm{P}$ zoning due to prolonged residence times)

or more recharge events during their life span in a shallow reservoir.

\section{Samples}

We focused on three tephra deposits produced during two of the largest recent eruptions (1957 and 1850 A.D.) in order to investigate the processes of magma recharge prior to a voluminous eruption. The 1957 eruption is a product of the N-S-oriented summit vents, whereas the $\sim 1850$ eruption (Fissural 3 event of Naranjo and Moreno 2005) is from two E-W-oriented fissures on the lower, northeast flank. The 1957 eruption lasted 2 years (1955-1957) and produced three voluminous lava flows on the northern, northeastern, and eastern flanks of the volcano. Little is known about the temporal evolution of the eruption, but only one $\sim 10$-cm-thick tephra unit could be stratigraphically linked to this eruption, and it must correspond to a paroxysm. The $\sim 1850$ AD eruption, which is classified as the products of the "Fissural 3" eruption by Naranjo and Moreno (2005), occurred from two parallel chains of cones on the northeastern flank of the volcano. Voluminous lava flows are associated with the younger set of cones. Related tephra 
directly underlie the 1957 tephra layer. Two locally thick tephra layers ("lower" and "upper") could be traced back to the two sets of cones and are referred to as LF3 and UF3. The choice of tephra relative to lava allows us to focus on reservoir processes only because of the limited amount of crystallization during eruption.

This investigation is complementary to a previous study of olivine-hosted melt inclusions (Bouvet de Maisonneuve et al. 2012), and we use the same samples. Mafic scoriae $2-5 \mathrm{~cm}$ in diameter were collected from two proximal stratigraphic sections located to the northeast of the volcano (in the direction of prevailing winds). Samples were gently crushed, and olivine grains were handpicked under a binocular microscope from the $>0.5 \mathrm{~mm}$ size fraction. These grains were mounted in epoxy and polished. Three representative crystals were selected from each of the tephra units considered (1957, UF3, and LF3) on the basis of their well-developed crystal faces.

\section{Methods}

\section{Electron probe microanalyses (EPMA)}

$\mathrm{Fe}, \mathrm{Mg}, \mathrm{Mn}, \mathrm{Ni}$, and $\mathrm{Ca}$ zoning profiles were measured by EPMA (JEOL 8200 at the University of Lausanne, Switzerland) at $15 \mathrm{kV}$ and $40 \mathrm{nA}$ with a focused beam. Counting time was 30/15 s (peak/background) for $\mathrm{Ca}, 10 / 5 \mathrm{~s}$ for $\mathrm{Si}$, and 20/10 s for the other elements. The relative error on major elements is around 1-2 \% for $\mathrm{SiO}_{2}, \mathrm{FeO}$, and $\mathrm{MgO}$; $7 \%$ for $\mathrm{CaO} ; 12 \%$ for $\mathrm{MnO}$; and $\sim 50-60 \%$ for $\mathrm{NiO}$ which was only barely above detection limit. $\mathrm{K}_{\alpha} \mathrm{X}$-ray intensity maps were obtained for all crystals in order to image the potential anisotropy or other complexities in zoning. Fe, $\mathrm{Mg}$, and Mn maps were obtained with a focused beam at $40 \mathrm{nA}$ for all UF3 olivines (C11, D14, E3) and most of LF3 olivines (A26, C13), and at $200 \mathrm{nA}$ for all 1957 olivines (A3, B1, B6) and one LF3 olivine (A27).

Additional $\mathrm{K}_{\alpha} \mathrm{X}$-ray intensity maps of $\mathrm{P}, \mathrm{Ca}, \mathrm{Mg}$, and $\mathrm{Cr}$ were obtained from selected parts of crystals A3 and B1 (1957 tephra) using a field emission gun electron microprobe (JEOL-JXA-8530F) at the Nanyang Technological University (Singapore). Analyses were conducted with a focused beam, an accelerating voltage of $20 \mathrm{kV}$, a current of $340 \mathrm{nA}$, and a dwell time of $800 \mathrm{~ms}$.

\section{Laser ablation inductively coupled plasma mass spectrometry (LA-ICP-MS)}

Major and trace element abundances in the olivine phenocrysts and the adjacent glassy matrix were analyzed in situ by LA-ICP-MS at the Research School of Earth Sciences, ANU (Canberra). The procedure was identical to that of Spandler and O'Neill (2010). The LA-ICP-MS system consisted of an Agilent 7500 quadrupole ICP-MS coupled to a Resonetics 193-nm excimer laser with a custom-built, fast-washout ablation chamber. $\mathrm{He}-\mathrm{H}_{2}$ mixture was used as the aerosol transport gas. Laser optics, ablation cell geometry, and signal smoothing devices are described in Eggins et al. (2003). The instrument was tuned to ensure low backgrounds and low oxide production levels $(<0.5 \% \mathrm{ThO})$. Laser repetition rate was $5 \mathrm{~Hz}$, and counting time was $30 \mathrm{~s}$ for both the gas background and the ablating olivine or glass. ${ }^{29} \mathrm{Si}$ served as the internal standard for olivine and glass, on the basis of $\mathrm{Si}$ contents previously measured by electron probe. The NIST 610 synthetic glass was used for external standardization, and it was analyzed in the same manner as unknowns. The average element abundances were taken from the Georem database (Jochum et al. 2005). All data were reduced according to the scheme of Longerich et al. (1996).

A combination of scanning traverses and point analyses was used to measure zoning profiles in multiple directions within single crystals. For scanning traverses, the laser was focused into a $\sim 100 \times 6 \mu \mathrm{m}$ rectangular beam oriented parallel to the olivine-glass interface. Following background counting for $30 \mathrm{~s}$, the sample was traversed continuously beneath the laser at a rate of $1 \mu \mathrm{m} / \mathrm{s}$. All traverses were started at the interior of the olivine crystal and ended by ablating "clean" glass (i.e., glass far enough from the crystal boundary that it had not been covered with sputtered olivine). The traverses were positioned to avoid cracks and melt inclusions as much as possible. Eight elements were recorded every $0.5 \mathrm{~s}$ for all traverses in order to maximize analytical precision. $\mathrm{Cr}, \mathrm{V}, \mathrm{Ni}, \mathrm{Ti}, \mathrm{P}, \mathrm{Al}$ were obtained first, and $\mathrm{Co}, \mathrm{Mn}, \mathrm{Sc}, \mathrm{Y}, \mathrm{Ca}, \mathrm{Na}$ were measured in some cases by scanning the same traverse a second time after cleaning and slight polishing of the crystals to remove the sputtered material. Si and Fe were systematically measured in both traverses. Additional analytical profiles were obtained using a series of conventional spot analyses on olivine. The same elements were analyzed in a series of 5-13 ablation spots with diameters of $30 \mu \mathrm{m}$. Point traverses ended oblique to the olivine-melt interface for the purpose of obtaining higher resolution zoning profiles at the rim. An average of three spot analyses were performed in the matrix glass attached to the olivine rims of each crystal.

\section{Electron backscatter diffraction (EBSD)}

EBSD was performed on the selected phenocrysts in order to determine the orientation of the crystal lattice, which is necessary for kinetic modeling of anisotropic diffusion in olivine. Olivine crystals were first polished stepwise down to $0.5-\mu \mathrm{m}$ diamond paste and further polished for $1 \mathrm{~h}$ using 25-nm colloidal silica suspension $(\mathrm{pH} 9.8)$ on a Buehler 
Phoenix 4000 polisher. No carbon coating was applied in order to ensure optimal EBSD pattern quality.

EBSD measurements were taken at the University of Lausanne (Switzerland) using a Tescan Mira LMU SEM operated at $20-\mathrm{kV}$ acceleration voltage, $\sim 1.5-\mathrm{nA}$ probe current, $23 \mathrm{~mm}$ working distance and $70^{\circ}$ sample tilt, and equipped with a Nordlys $\mathrm{S}$ detector and the Oxford Instruments Channel 5.10 software package. A thorough coverage of the EBSD technique can be found in Prior et al. (1999). EBSD patterns were collected through point analysis and indexed using the Forsteri.cry match unit $(a=4.756 \AA, b=10.207 \AA, c=5.980 \AA)$ from the HKL database. No change in crystallographic orientation was detected within individual grains, in good agreement with the magmatic (i.e., plastically undeformed) nature of the phenocrysts.

\section{A new lattice Boltzmann model for two-dimensional (2D) diffusion}

We conducted 2D diffusion modeling of crystals with complex geometries with a new lattice Boltzmann model running in MATLAB $\odot$. Our model allows us to directly input bitmap images from EPMA X-ray maps to constrain the geometry and boundary conditions for each diffusion simulation. Crystal boundaries are set to constant concentrations using the method described in Huber et al. (2011b), while the initial core concentration inside the crystal domain is set according to the EPMA and LA-ICP-MS data. In the following, we present a brief overview of the novel lattice Boltzmann model we developed for solving diffusion anisotropy in 2D.

The lattice Boltzmann method (LBM) is rooted in kinetic theory wherein the evolution of particle distribution functions replaces macroscopic partial differential equations (here the diffusion equation). According to Boltzmann's equation, the probability $f(\mathbf{x}, \mathbf{v}, t)$ of finding a particle at position $\boldsymbol{x}$, time $t$ with velocity $\boldsymbol{v}$ evolves according to

$f(x+v \mathrm{~d} t, v, t+\mathrm{d} t)-f(x, v, t)=\Omega(x, v, t)$,

in which $\Omega$ is the collision operator that describes interactions among particles (conserves mass and momentum of particles). The collision operator is simplified to a single relaxation time operator (BGK) defined by

$\Omega(x, v, t)=-\frac{1}{\tau}\left[f(x, v, t)-f^{e q}(x, v, t)\right]$,

where $f^{e q}$ stands for the local equilibrium particle distribution functions toward which the distribution relaxes exponentially over a timescale controlled by the relaxation time $\tau$. LBM schemes for 2D diffusion employ a four or five velocity discretization $\mathbf{v}=\mathbf{e}_{\mathrm{i}}$, where the $\mathbf{e}_{\mathrm{i}}$ 's are vectors pointing to nearest grid point toward north-east-south-west and sometimes a rest velocity $\mathbf{e}_{0}=(0,0)$. The equilibrium distribution functions are conventionally defined by

$f_{i}^{e q}\left(x, e_{i}, t\right)=w_{i} C(x, t)$,

where the values of $w_{i}$ correspond to "lattice weights" and sum to one $\left(\sum_{i} w_{i}=1\right)$ to ensure mass conservation. $C(x, t)$ is the local concentration of interest for the diffusion process. The diffusion coefficient depends on the choice of relaxation time (isotropic case)

$D=c_{s}^{2} \mathrm{~d} t\left(\tau-\frac{1}{2}\right)$,

where $c_{s}^{2}$ is a constant defined by the discretization scheme (topology of the lattice used). This lattice Boltzmann model retrieves the standard (isotropic) diffusion equation in two or three dimensions (depending on the choice of lattice) after a multiscale expansion (Wolf-Gladrow 2000; Huber et al. 2010, 2011a, b).

The case of anisotropic diffusion requires a different strategy, and to our knowledge, the method described here has never been studied before. The problem associated with definitions of the equilibrium distribution functions $f^{e q}$ and the lattice weights $w_{i}$ is that they force isotropy in the model. The standard definition of $f^{e q}$ requires that distributions relax to an isotropic state. We therefore define an alternative set of lattice weights, here for $2 \mathrm{D}$ anisotropic diffusion

$w_{i}=\frac{\alpha\left(D \otimes e_{i}\right)^{2}}{D_{y}^{2}}$,

the tensorial product between the diffusion tensor $\boldsymbol{D}$ and the discrete lattice velocities $\boldsymbol{e}_{\mathbf{i}}$ is squared, and $\alpha$ is a normalization constant to close the sum of $w_{i}$ to 1 . We find that

$\alpha=\frac{1}{2}\left(\frac{D_{y}^{2}}{D_{x}^{2}+D_{y}^{2}}\right)$.

This new definition for the lattice weights allows the equilibrium distribution to become anisotropic, and the amount of anisotropy is fixed by the ratio $\Delta=\left(D_{x} / D_{y}\right)^{1 / 2}$.

After a multiscale expansion (see details of the derivation and validation in the Electronic Supplementary Material-ESM), we find that a $2 \mathrm{D}$ anisotropic diffusion equation is recovered

$\frac{\partial C}{\partial t}=\frac{\partial}{\partial x}\left(D_{x} \frac{\partial C}{\partial x}\right)+\frac{\partial}{\partial y}\left(D_{y} \frac{\partial C}{\partial y}\right)$

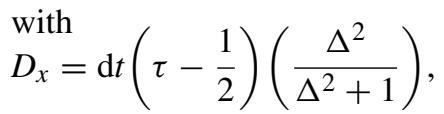

$D_{y}=\mathrm{d} t\left(\tau-\frac{1}{2}\right)\left(\frac{1}{\Delta^{2}+1}\right)$. 
For all simulations conducted in this study, olivine minerals are first oriented so as to have the lattice grid aligned with the principal directions of diffusion $D_{x}$ and $D_{y}$ (although the association of a particular axis with either $D_{x}$ or $D_{y}$ is not necessary). In our crystals, $D_{\mathrm{x}} \sim D_{[100]}$ or $D_{[010]}$ and $D_{\mathrm{y}} \sim D_{[001]}$. For full generality, we use the dimensionless Fourier number Fou $=\max \left(D_{x}, D_{y}\right) \times$ time/length $^{2}$ to characterize the best fit, using the minimum least square error in concentration integrated over the grain. Resorting to a Fourier number allows us to constrain $D(T) \times t$ instead of time for each $D(T)$ as discussed in Huber et al. (2011b), which can vary depending on the assumed temperature at which diffusion is inferred to occur.

\section{Results: zoning patterns and partition coefficients}

There is good agreement between the profiles obtained by EPMA and LA-ICP-MS, as well as for Fe between the two successive scans performed along the same traverse by LAICP-MS (ESM Fig. 2). Multiple traverses obtained from a single crystal overlap for each element in common, thereby confirming the reproducibility of the method. We refer exclusively to the LA-ICP-MS data for profiles described in the following sections (Figs. 2, 4; ESM Fig. 3).

The fourteen elements analyzed can be grouped according to the zoning patterns they display. In terms of Forsterite content (Fo), the olivine phenocrysts from all three units display homogeneous, non-zoned cores surrounded by 100 - to $200-\mu m$-wide zoned rims (Fig. 2). Seven of nine phenocrysts are reversely zoned, and two (1957-B1 and UF3-D14) are normally zoned. $\mathrm{Ni}, \mathrm{Mn}, \pm \mathrm{Ca}$, and Y closely correlate-positively or negatively-with Fo, displaying variably developed zoning at the rim but no zoning in the core. More specifically, $\mathrm{Mn}$ is negatively correlated with Fo in all crystals, $\mathrm{Ni}$ is positively correlated with Fo in eight crystals (it does not vary in LF3-C13), Ca is negatively correlated with Fo in all crystals but shows low-amplitude variations often over a narrow distance, and $\mathrm{Y}$ is negatively correlated with Fo in four crystals and shows no variations in the other five.

$\mathrm{P}$ and $\pm \mathrm{Al}$ variations, on the other hand, do not correlate with Fo. $\mathrm{P}$ fluctuations occur in the cores of at least five crystals and are close to melt inclusions (1957-A3, B1, UF3-C11, E3, LF3-C13, 土LF3-A26, A27). Al fluctuations occur in the cores of at least two crystals (1957-A3, UF3E3, \pm LF3-A27). P also shows fluctuations or enrichments in the rims of all crystals, while Al fluctuations occur in the rims of three crystals (UF3-C11, LF3-A26, C13, $\pm 1957-$ A3). These irregular zoning patterns are not easily reconcilable within a crystal when considering one-dimensional traverses but can be understood after comparison with 2D
X-ray intensity maps (Fig. 3). High-P zones in the cores of crystals 1957-A3 and 1957-B1 have skeletal shapes that often surround melt inclusions (e.g., Welsch et al. 2014). Low-P zones envelope these features and infill the spaces between skeletal branches. The fluctuations at the rims are moderately enriched in $\mathrm{P}$ and tend to be more concentric, sometimes giving the impression of oscillatory zoning.

Concentrations of $\mathrm{Ti}, \mathrm{Sc}, \mathrm{V}, \pm \mathrm{Cr}$ display zoning patterns that tend to correlate both with Fo at the rim and $\mathrm{P}$ in the core. Typically, they record a few oscillations that coincide in space with the high-P skeletal zones in the core but also show normally or reversely zoned rims that coincide with changes in Fo (e.g., 1957-A3, 1957-B1, UF3-E3). Ti, Sc, and $\mathrm{V}$ are negatively correlated with Fo and covary with each other. Cr systematically increases toward the rim.

From the descriptions above, we propose three groups of elements: (Group 1) Ni, Mn, $\pm \mathrm{Ca}$, and \pm Y follow Fo with concentric zoning at the rims but no zoning in the cores; (Group 2) $\mathrm{P}$ and $\pm \mathrm{Al}$ display skeletal enrichments in the core and occasionally concentric and moderate enrichments at the rim; and (Group 3) $\mathrm{Ti}, \mathrm{Sc}, \mathrm{V}$, and $\pm \mathrm{Cr}$ follow both Fo and $\mathrm{P}$ with skeletal enrichments in the core and concentric zoning at the rims. Due to the absence of chemical zoning and low-precision data, $\mathrm{Co}$ and $\mathrm{Na}$ will not be discussed further.

Rim compositions are similar for Groups 1 and $\mathbf{3}$ elements for all crystals, whereas cores show a range in composition in both major and trace elements (Fig. 4). This is particularly pronounced for the 1957 sample. Core compositions were obtained by averaging the non-zoned central portions of crystals. Rim compositions correspond to the outer $5 \mu \mathrm{m}$. Compositional variation trends between core and rim are similar for all three tephra units, with cores ranging from $\mathrm{Fo}_{73-82}$ and rims plotting at the high-Fo end of the range $\left(\mathrm{Fo}_{78-79}, \mathrm{Fo}_{77-80}, \mathrm{Fo}_{79-82}\right.$, in the 1957, UF3 and LF3 units, respectively). $\mathrm{Mn}, \mathrm{V}, \mathrm{Sc}, \mathrm{Ti}, \pm \mathrm{Ca}$, and $\pm \mathrm{Y}$ are negatively correlated with $\mathrm{Fo}$, whereas $\mathrm{Ni}$ and $\mathrm{Cr}$ are positively correlated.

Partition coefficients between olivine rims and adjacent matrix glass were computed for each trace element from the LA-ICP-MS data. Major element matrix glass compositions measured by LA-ICP-MS are in good agreement with EPMA results; $\mathrm{Al}, \mathrm{Na}, \mathrm{Ca}, \mathrm{Fe}$ are in the same range as what was measured previously (ESM Fig. 4; Bouvet de Maisonneuve et al. 2012). Partition coefficients were estimated by dividing the concentrations of elements of interest in olivine rims (outer $5 \mu \mathrm{m}$ ) by concentrations in adjacent glass. They are on the order of $\sim 2$ for $\mathrm{Fe}$ and $\mathrm{Mn}, \sim 1$ for $\mathrm{Cr}, \sim 6$ for $\mathrm{Co}, 14-30$ for $\mathrm{Ni}, \sim 10^{-1}$ for $\mathrm{Sc}$, and $\sim 10^{-2}$ for $\mathrm{Ti}$ and $\mathrm{V}$ (Table 1), which are in agreement with values reported in the literature and suggest that the glass and rims are close to chemical equilibrium. 


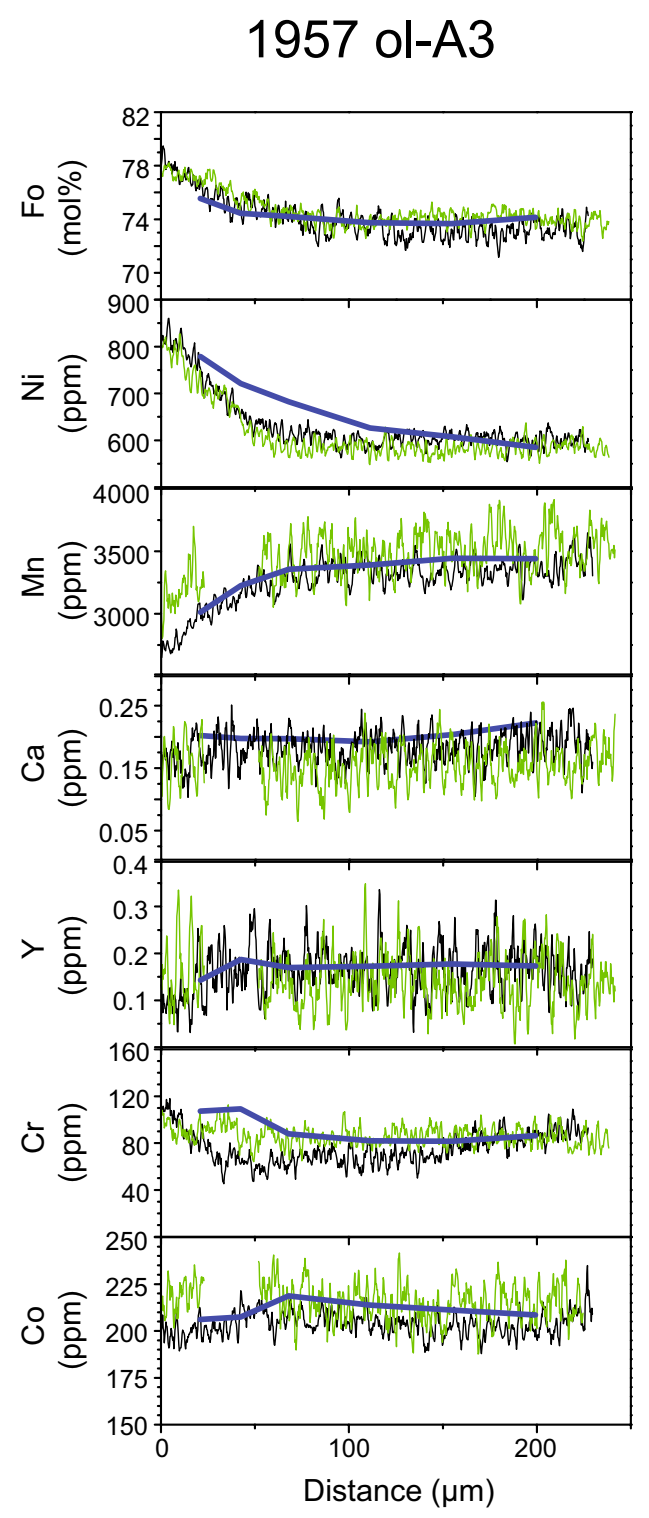

Fig. 2 LA-ICP-MS traverses in olivine crystal A3 from the 1957 tephra deposit. Data for all other crystals is given in ESM Fig. 3. The horizontal axis shows the distance from the rim. Locations of traverses are shown in the upper-right corner on a picture of the crystal taken in reflected light (the color of the label corresponds to the color of the line in the plots) and on an X-ray intensity map of $\mathrm{Mg}$.

\section{Implications for magmatic processes at Llaima}

Deciphering the information contained in compositional zoning of igneous minerals relies on an understanding of the processes and conditions that control the variable uptake of a given element by a specific mineral. Dominant magmatic processes in the Llaima system are (1) mafic magma recharge; (2) consequent crystal-mush formation

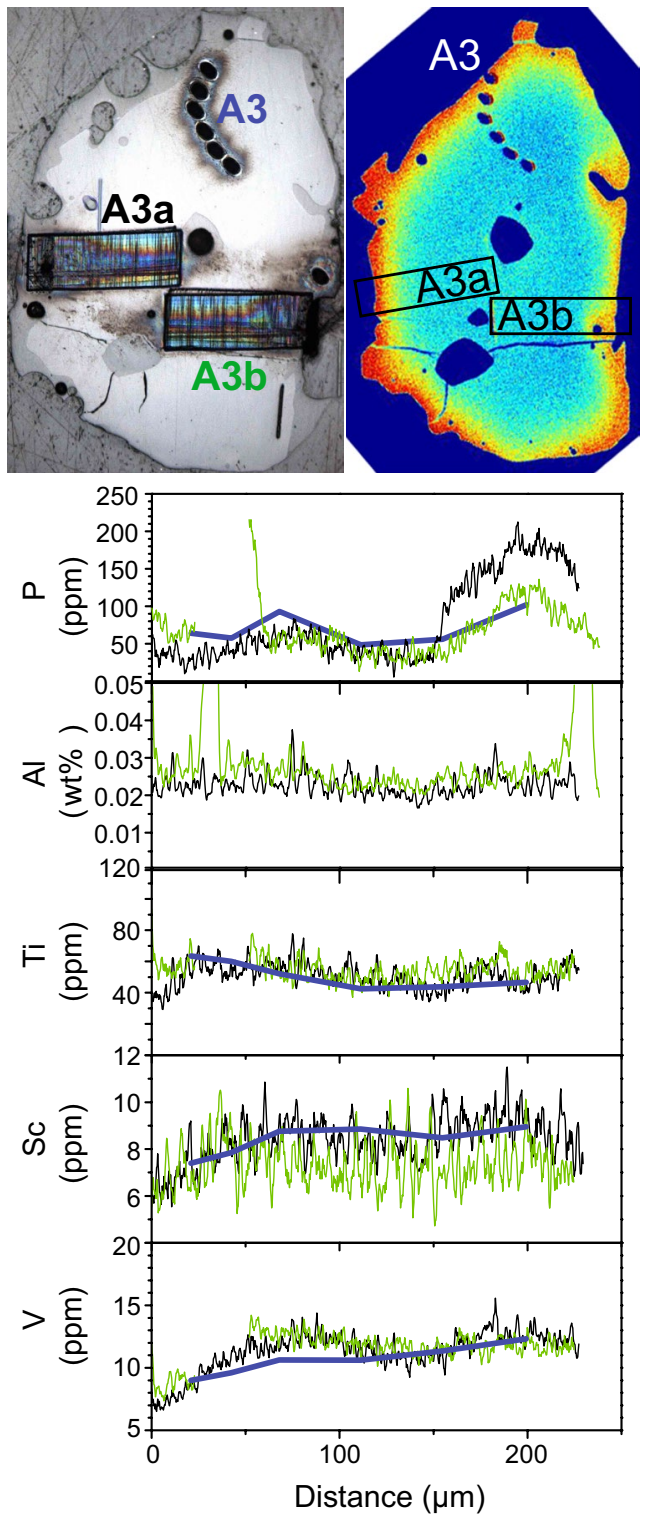

Element concentrations collected with LA-ICP-MS as point traverses are shown on data plots as blue and red lines; those collected using scanning traverses are shown in black, green, and gray. The distance from the rim in the point traverses was geometrically corrected to be perpendicular to the olivine-glass interface

by decompression-related degassing, which implies a range of crystallization conditions at low pressure; and (3) modification and disruption of resident crystal mush by subsequent recharge events (Fig. 1). These processes should leave chemical fingerprints in associated crystals that will be reflected in observed differences in zoning patterns for Groups 1, 2, and 3 elements (i.e., Fo-like, P-like, and hybrid, respectively). 

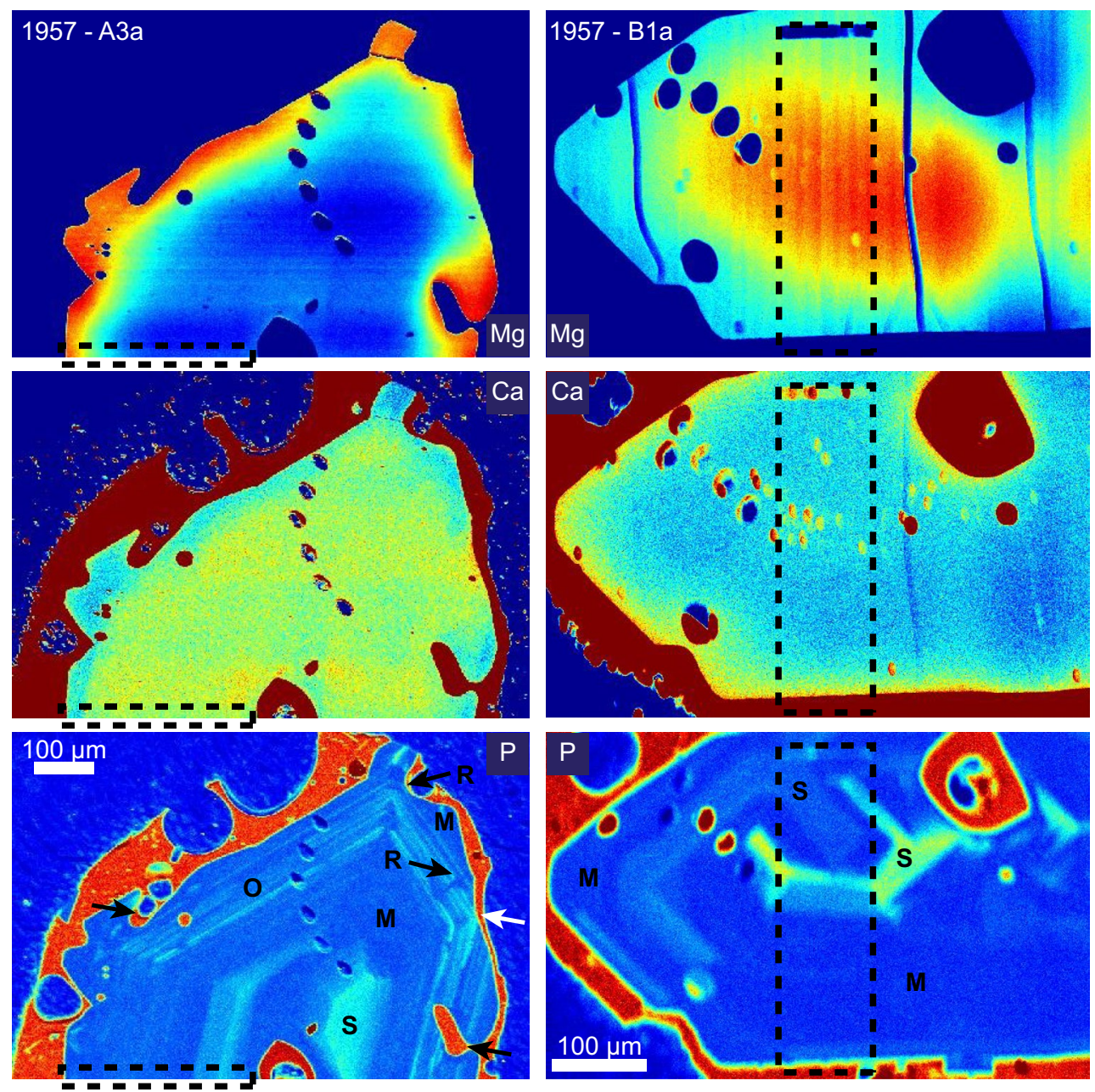

Fig. 3 EPMA $\mathrm{K}_{\alpha} \mathrm{X}$-ray intensity maps of $\mathrm{Mg}, \mathrm{Ca}$, and $\mathrm{P}$ obtained from selected parts of two crystals from the 1957 tephra. Crystal A3 is reversely zoned in Fo content, suggesting that it originated from mush. It's $\mathrm{P}$ zoning reveals a complex history with initial nucleation and skeletal growth triggered by magma recharge (S), slower growth during residence in crystal mush $(\mathrm{M})$, and two recharge events that

\section{Changes in magma composition and Fo zoning}

Most of the major and trace element zoning can be attributed to changes in magma composition and temperature. The dominance of reversely zoned olivines in Llaima tephra is interpreted as the product of mafic magma recharge prior to eruption, thereby driving the resident magma to less evolved, Fo-rich compositions, and hotter conditions (Bouvet de Maisonneuve et al. 2012). The strong correlations between Fo contents and abundances of Group 1 (Fo-like) and Group 3 (hybrid) elements suggest that their concentrations are also controlled by magma composition. Converging rim compositions but variable core compositions are observed for $\mathrm{Fo}, \mathrm{Mn}, \mathrm{Ni}, \mathrm{Ca}, \mathrm{Y}, \mathrm{Sc}$, $\mathrm{V}, \pm \mathrm{Ti}$, and $\mathrm{Cr}$ in all three units (Figs. 2, 4). These elements, therefore, record a mixing event between evolved

resorbed the crystal rim and produced embayments (R). Crystal B1 is normally zoned, suggesting that it originated from recharge magma. It records its initial nucleation and skeletal growth $(\mathrm{S})$ followed by a slower crystallization episode (M) as recharge magma was mixing with crystal mush

resident magmas and mafic recharge magmas, followed by homogenization of the resulting hybrid magma prior to eruption.

These mixing events involve broadly cogenetic magmas, as trace element variations can be explained by olivine crystallization alone and they are similar for the crystals of three different eruptions. Positive correlations between Fo contents, Ni, and $\mathrm{Cr}$ (Fig. 4) are consistent with estimates of partition coefficients that are greater than one (Table 1). As compatible trace elements are depleted in the melt as it crystallizes, more evolved olivine compositions display lower $\mathrm{Ni}$ and $\mathrm{Cr}$. Conversely, negative correlations of Fo with $\mathrm{Ti}, \mathrm{V}, \mathrm{Sc}, \pm \mathrm{Ca}$, and $\pm \mathrm{Y}$ are in agreement with partition coefficients smaller than one, as these incompatible trace elements are enriched in the melt as it crystallizes. $\mathrm{Mn}$ is compatible in olivine (partition coefficient $>1$ ) and 
Fig. 4 Trace element composition as a function of Fo content in the olivines of the tephra from the 1957, UF3, and LF3 ( 1850) eruptions. Core compositions were obtained by averaging the non-zoned central parts of crystals, and rim compositions correspond to the outer $5 \mu \mathrm{m}$. Cores display a range in major and trace element composition, whereas rims are similar in composition within and between the three tephra units

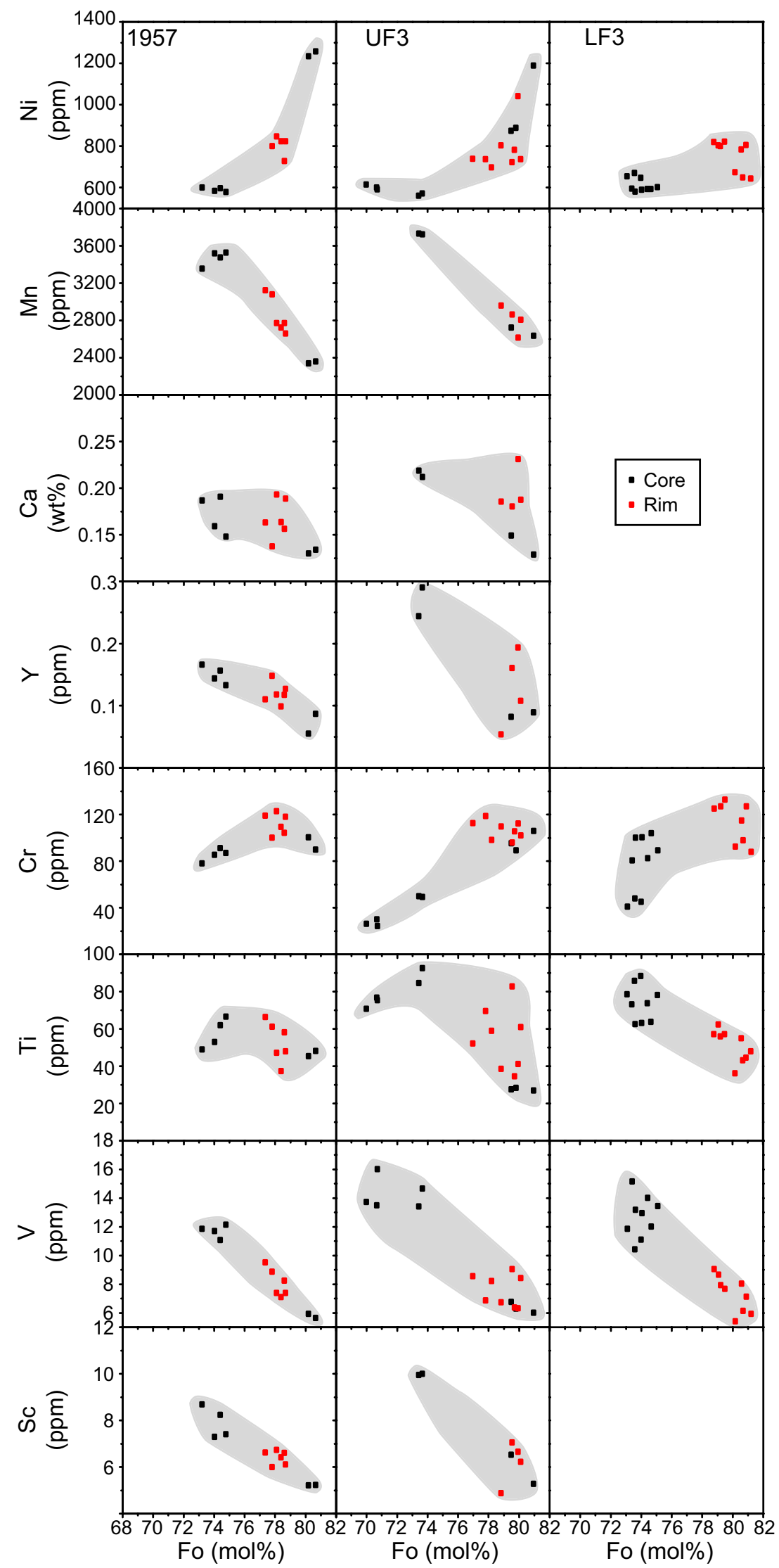


Table 1 Calculated olivine/melt partition coefficients $\left(K_{\mathrm{M}}\right)$

\begin{tabular}{lllrll}
\hline Element & $K_{\mathrm{M}}$ & $2 \mathrm{SD}$ & $n$ & Literature range & Refs. \\
\hline $\mathrm{Al}$ & $2.05 \times 10^{-3}$ & $6.68 \times 10^{-4}$ & 22 & $(1.0-2.0) \times 10^{-2}$ & Beattie (1994) \\
$\mathrm{Y}$ & $5.79 \times 10^{-3}$ & $1.91 \times 10^{-3}$ & 7 & $(4.0-10) \times 10^{-3}$ & Nielsen et al. (1992), Beattie (1994), Nikogosian and Sobolev (1997) \\
$\mathrm{Ti}$ & $8.15 \times 10^{-3}$ & $1.59 \times 10^{-3}$ & 22 & $(7.0-20) \times 10^{-2}$ & Dunn (1987), Nikogosian and Sobolev (1997) \\
$\mathrm{Ca}$ & $2.05 \times 10^{-2}$ & $1.61 \times 10^{-3}$ & 7 & $(2.0-4.0) \times 10^{-2}$ & Dunn (1987), Beattie (1994) \\
$\mathrm{V}$ & $2.51 \times 10^{-2}$ & $2.94 \times 10^{-3}$ & 22 & $(2.0-9.0) \times 10^{-2}$ & Duke (1976), Gaetani and Grove (1997) \\
$\mathrm{P}$ & $7.66 \times 10^{-2}$ & $2.81 \times 10^{-2}$ & 22 & 0.1 & Brunet and Chazot (2001) \\
$\mathrm{Sc}$ & 0.18 & $2.68 \times 10^{-2}$ & 7 & $0.12-0.38$ & Nielsen et al. (1992), Beattie (1994) \\
$\mathrm{Cr}$ & 1.15 & 0.29 & 22 & $0.63-1.85$ & Beattie (1994), Gaetani and Grove (1997) \\
$\mathrm{Mn}$ & 1.85 & $6.35 \times 10^{-2}$ & 7 & $0.62-1.79$ & Watson (1977), Gaetani and Grove (1997) \\
$\mathrm{Fe}$ & 2.02 & 0.12 & 22 & $0.5-3.0$ & Beattie (1994) \\
$\mathrm{Co}$ & 6.12 & 0.63 & 7 & $3.63-6.3$ & Duke (1976), Gaetani and Grove (1997) \\
$\mathrm{Ni}$ & 22.2 & 10.7 & 22 & $22.0-36.4$ & Dostal et al. (1983), Villemant (1988) \\
\hline
\end{tabular}

All data obtained by LA-ICP-MS

" $n$ " is the number of individual values used for calculation of $\mathrm{K}_{\mathrm{M}}$, and " $2 \mathrm{SD}$ " is the two standard deviation of each dataset

is negatively correlated with Fo content, as the Mn partition coefficient is very close to that of Fe. Trace element contents of olivines support the model of Llaima magmas being produced by a balance between (1) recharge of shallow magma reservoirs by the injection of mafic crystal-poor magma, (2) rapid and voluminous crystallization following decompression and degassing of the recharge magma, and (3) subsequent eruptions of crystal-rich basaltic-andesitic magma (Fig. 1; Bouvet de Maisonneuve et al. 2012, 2013).

The simple zoning patterns defined by Fo variations and Group 1 elements, and the restriction of changes to outer rims, render these elements unable to reconcile the olivine record with the more complex plagioclase record (Bouvet de Maisonneuve et al. 2013). If elements such as $\mathrm{Mg}, \mathrm{Fe}$, $\mathrm{Mn}, \mathrm{Ni}, \mathrm{Ca}$, and $\mathrm{Y}$ only are considered, Llaima olivines can be interpreted to record no more than one recharge event. However, Group 2 (P-like) and Group 3 (hybrid) elements do show variations in olivine cores and may provide information on earlier mixing events or other magmatic processes.

\section{Kinetics of olivine growth and $P$ zoning}

Phosphorus displays complex zoning patterns including skeletal shapes that are not correlated with Fo content or other divalent constituents such as $\mathrm{Mn}$ and $\mathrm{Ca}$. A similar behavior for $\mathrm{P}$ has previously been described in natural and experimental olivines and was attributed to crystal growth kinetics (Milman-Barris et al. 2008; Welsch et al. 2013, 2014; Shea et al. 2015). The chemical variations are due to the excessive incorporation of $\mathrm{P}$ during rapid growth (kinetic disequilibrium partitioning, boundary layer effect) rather than changes in the bulk $\mathrm{P}$ content of the magma. As $\mathrm{P}$ is a slowly diffusing element in silicate melt (Baker
2008; Watson et al. 2015), its concentration increases in boundary layers adjacent to rapidly growing crystals, and it is thereby increasingly incorporated by the olivine due to local partitioning constraints. Phosphorus is also generally believed to be a slow-diffusing element in olivine (Ito and Ganguly 2006; Spandler et al. 2007), although recent data show much higher diffusivities (Watson et al. 2015). The sharp features of $\mathrm{P}$ zoning in natural crystals favors a model where internal compositional variations are faithfully preserved over long timescales.

Kinetic disequilibrium partitioning of $\mathrm{P}$ between olivine and host melt due to the presence of a boundary layer in the melt can be characterized using the equations of Albarède and Bottinga (1972). Assuming an infinite liquid reservoir, the temporal evolution of the concentration of a given trace element in a growing crystal $\left(C_{s}^{t}\right)$ is given by Eq. (9). In this situation, the crystal is growing at a rate, $G$, that is too rapid for diffusion in the liquid to maintain equilibrium between the crystal boundary and the far-field melt composition. Hence,

$$
\begin{aligned}
\frac{C_{s}^{t}}{C_{0}}= & \frac{1}{2 K} \times\left\{1+\operatorname{erf}\left(\frac{1}{2} \sqrt{\frac{G x^{\prime}}{D}}\right)+(2 K-1)\right. \\
& \left.\times \exp \left(-K(1-K) \sqrt{\frac{G x^{\prime}}{D}}\right) \times \operatorname{erfc}\left(\frac{1}{2}(2 K-1) \sqrt{\frac{G x^{\prime}}{D}}\right)\right\}
\end{aligned}
$$

where $C_{0}$ is the initial, equilibrium trace element concentration in the solid, $K$ is the partition coefficient, $D$ is the diffusivity of the element in the melt, and $x^{\prime}$ is the half thickness of the crystal that started to grow at time 0 (adapted from Eq. 9 of Albarède and Bottinga 1972). This analytical formulation shows that for a given amount of growth $\left(x^{\prime}\right)$, the excessive incorporation of nominally highly incompatible 


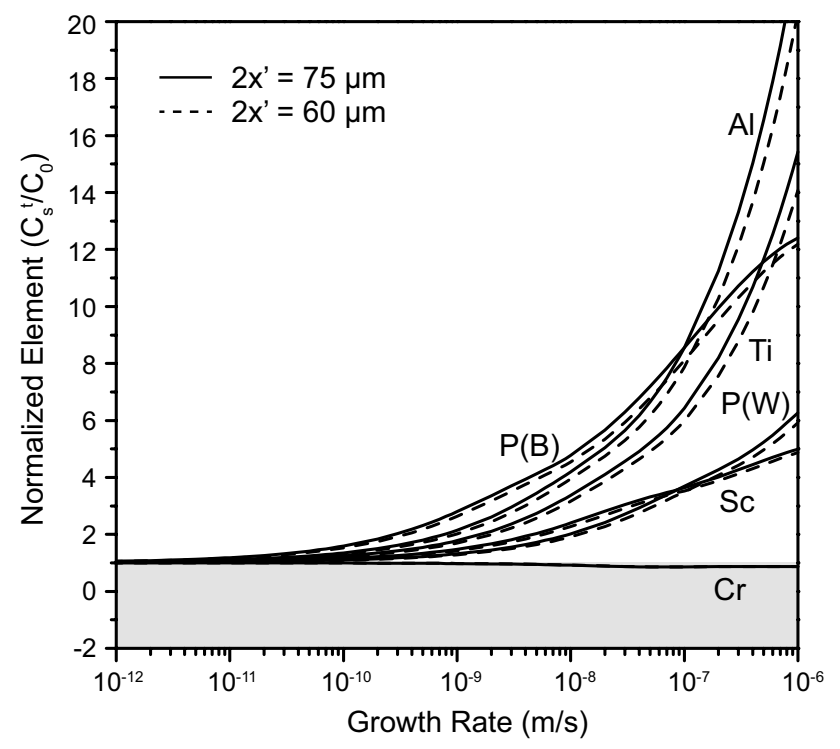

Fig. 5 Kinetically controlled enrichments of $\mathrm{P}, \mathrm{Al}, \mathrm{Ti}$, and $\mathrm{Sc}$ and depletion of $\mathrm{Cr}$ predicted by Eq. 9 as a function of crystal growth rate. (B) and (W) denote $\mathrm{P}$ enrichments when the data of Baker (2008) and Watson, et al. (2015) are used, respectively, for the diffusivity of $\mathrm{P}$ in basaltic melt. X' corresponds to the width of the enriched zone, $75 \mu \mathrm{m}$ in the case of crystal 1957-A3, and $60 \mu \mathrm{m}$ in the case of crystal 1957-B1

trace elements $\left(C_{s}^{t} / C_{0}\right)$ rapidly increases with the rate at which the crystal grows (Fig. 5).

The application of this model to natural data permits evaluation of the growth rates at which high-P skeletal cores were formed. P contents of crystals 1957-A3 and 1957-B1 were normalized to the lowest, presumably equilibrium value, yielding an estimate of the magnitude of excessive incorporation $\left(C_{s}^{t} / C_{0}\right.$; Fig. 6). Partition coefficients taken from our data are shown in Table 1. Element diffusivities in the melt are taken from Zhang et al. (2010), Baker (2008), and Watson et al. (2015) and are reported in Table 2. There is a difference of one order of magnitude in the diffusivity of $\mathrm{P}$ in dry basaltic melt between the experiments of Baker (2008) and those of Watson et al. (2015), despite similar compositions, experimental setups, and conditions. The skeletal cores of crystals 1957-A3 and 1957$\mathrm{B} 1$ have branches that are around 75 and $60 \mu \mathrm{m}$ in width, and these have $\mathrm{P}$ contents that are factors of up to 7 and 12 higher than the non-zoned portions. Extremely high growth rates, on the order of $7.10^{-8}$ and $7.10^{-7} \mathrm{~m} / \mathrm{s}$, respectively, are predicted with the slower diffusivity data of Baker (2008), and even greater $\left(2.10^{-6}\right.$ and $2.10^{-5} \mathrm{~m} / \mathrm{s}$, respectively) - likely unrealistic_-growth rates are predicted with the faster diffusivity data of Watson et al. (2015).

Equation (9) also predicts enrichments in other incompatible trace elements that diffuse slowly in melt, such as $\mathrm{Al}, \mathrm{Ti}$, and Sc, in response to rapid crystal growth (Fig. 5).
This is observed in Llaima olivine for Group 2 (P-like) and Group 3 (hybrid) elements that follow $\mathrm{P}$ zoning (Fig. 6). Enrichments are predicted to be on the order of 6 for $\mathrm{Al}$, 4.8 for $\mathrm{Ti}, 3.2$ for $\mathrm{Sc}$ in crystal $1957-\mathrm{A} 3\left(G=7.10^{-8} \mathrm{~m} / \mathrm{s}\right.$, $\left.2 x^{\prime}=75 \mu \mathrm{m}\right)$ and 14.5 for $\mathrm{Al}, 10.4$ for $\mathrm{Ti}, 4.4$ for $\mathrm{Sc}$ in crystal $1957-\mathrm{B} 1\left(G=7.10^{-7} \mathrm{~m} / \mathrm{s}, 2 x^{\prime}=60 \mu \mathrm{m}\right)$, but measured enrichments are much lower. The shortfall between observed and predicted enrichments can be explained by two factors: (1) Element enrichments in boundary layers ultimately are controlled by melt structure, thereby severely limiting enrichments of major melt components (e.g., Al content cannot increase by a factor of two or more), and (2) some of these elements have non-negligible diffusion rates in olivine, which will cause their initial enrichments to decay with time (e.g., Ti, Sc). Group 3 elements (hybrid) in combination with $\mathrm{P}$, therefore, yield information on rapid growth events and have the potential to record the time elapsed since compositional anomalies or gradients were formed.

\section{Reconciling the information from olivine and plagioclase zoning}

The 1D and 2D analyses of a large suite of major and trace element concentrations in several olivine grains show that, although most elements record only the latest part of the crystal's history (i.e., the last recharge event), elements such as $\mathrm{P}, \mathrm{Ti}, \mathrm{Sc}, \mathrm{V}, \pm \mathrm{Cr}$, and $\mathrm{Al}$ also record earlier events. The pattern of P zoning of crystal 1957-A3 is complex and suggests that this crystal experienced at least three recharge events. The skeletal core ("S" in Fig. 3) surrounding the melt inclusion formed immediately after crystal nucleation, likely in response to a first recharge event of hot mafic magma intruding the cooler reservoir of crystal mush. It is surrounded by a broad low-P region (marked "M"), which corresponds to slower crystal growth at lower degrees of undercooling, most likely during the crystal's residence time in crystal mush (hence the label "M"). Outwards from this low-P zone is a concentric, oscillatory-zoned, P-rich region, labeled "O" in Fig. 3. These $\mathrm{P}$ enrichments could be related to the high-P skeletal core ("S"), in which case both P-enriched regions would be touching in the third dimension and would have formed during the same rapid growth event [initial hollow hopper shape as shown by Welsch et al. (2014)]. On the other hand, they could be the product of a second rapid growth event. Two sequential rapid growth events (leaving a single connected P-rich skeleton) have been observed in skeletal olivines from Hawaii (Shea et al. 2015). Given that (1) the outer zone of crystal 1957A3 has significantly smaller P enrichments than the central skeleton (by a factor three to four), (2) it is apparently not physically connected to the central skeleton (although it could be an effect of the crystal cut), and (3) this crystal 
Fig. 6 Dominantly kinetically controlled, enrichments of $\mathrm{P}$, $\mathrm{Al}, \mathrm{Ti}, \mathrm{Sc}, \mathrm{V}$, and $\mathrm{Cr}$ measured in crystals $1957-\mathrm{A} 3$ and B1 as a function of distance from the rim. These excesses were measured by normalizing the concentration to the lowest, presumably equilibrium value

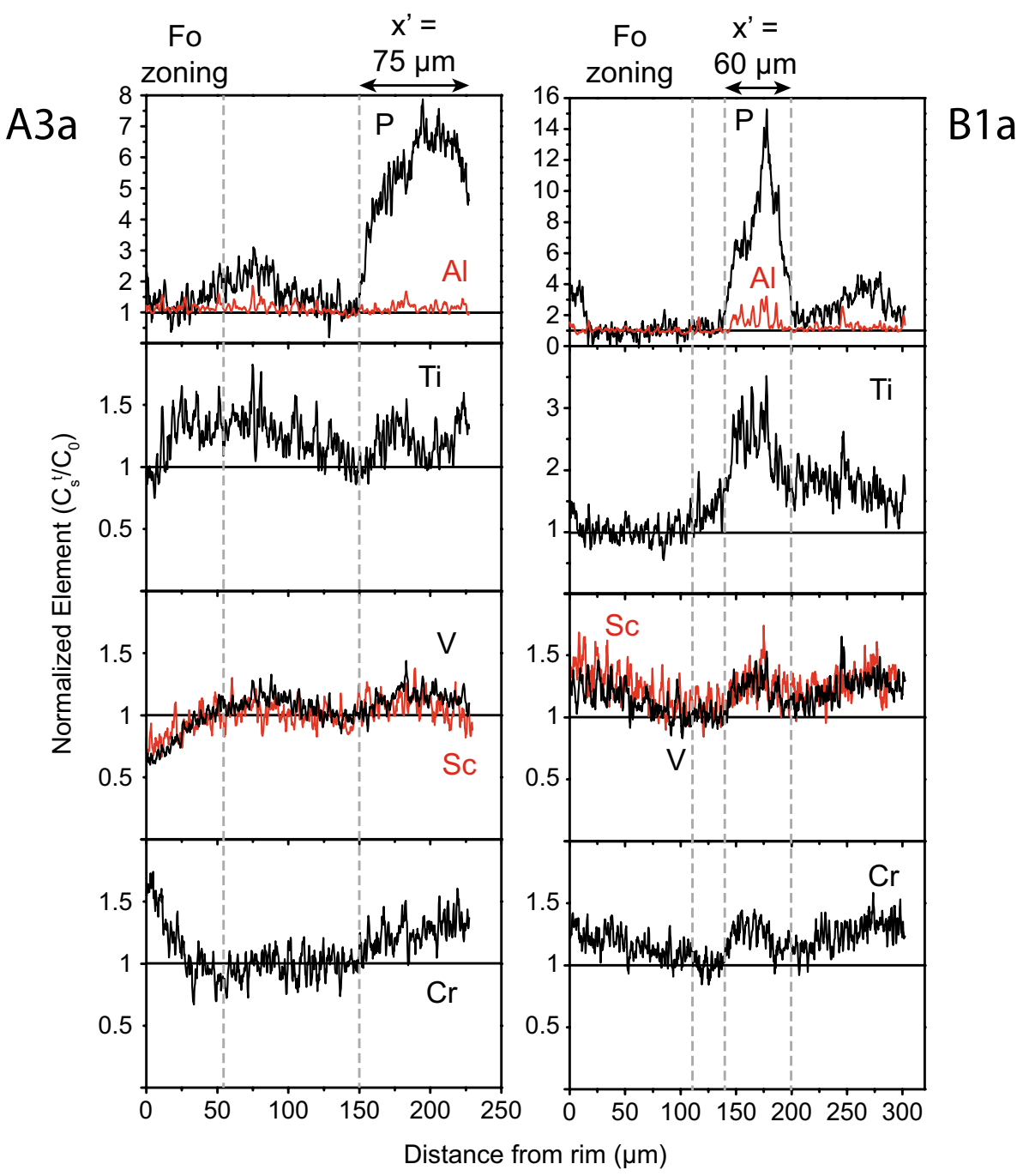

Table 2 Melt diffusivities of selected elements used in this study. Temperatures in diffusion equation are in $\mathrm{K}$

\begin{tabular}{llll}
\hline & $\mathrm{D}$ at $1050{ }^{\circ} \mathrm{C}\left(\mathrm{m}^{2} / \mathrm{s}\right)$ & Equation & Refs. \\
\hline $\mathrm{P}$ & $2.33 \mathrm{E}-14$ & $\operatorname{Exp}\left[-9.91-\frac{(28420 \pm 9874)}{T}\right]$ & Baker (2008) \\
& $7.88 \mathrm{E}-13$ & $\operatorname{Exp}\left[(-14.51 \pm 1.61)-\frac{(17680 \pm 2646)}{T}\right]$ & Watson et al. (2015) \\
$\mathrm{Al}$ & $1.69 \mathrm{E}-13$ & $\operatorname{Exp}\left[(-5.75 \pm 1.71)-\frac{(31293 \pm 2599)}{T}\right]$ & Zhang et al. (2010) \\
$\mathrm{Ti}$ & $3.52 \mathrm{E}-13$ & $\operatorname{Exp}\left[(-10.08 \pm 2.23)-\frac{(24600 \pm 3800)}{T}\right]$ & Zhang et al. (2010) \\
$\mathrm{Cr}$ & $1.03 \mathrm{E}-12$ & $\operatorname{Exp}\left[(-7.00 \pm 4.19)-\frac{27244 \pm 6343}{T}\right]$ & Zhang et al. (2010) \\
$\mathrm{Sc}$ & $4.78 \mathrm{E}-13$ & $\operatorname{Exp}\left[(-10.48 \pm 9.92)-\frac{23667 \pm 1007}{T}\right]$ & Lowry et al. (1982) \\
\hline
\end{tabular}

formed in a magmatic system that frequently experiences recharge events and eruptions, we believe that the outer P-rich zone more likely formed in a second event of rapid crystal growth. This zone is surrounded by a low-P region (marked "M"), which again corresponds to slower crystal growth at lower degrees of undercooling. The crystal rim has been affected by resorption (marked "R" in Fig. 3), which altered the euhedral morphology of the crystal. This is particularly evident on the eastern side of the crystal where $\mathrm{P}$ zoning shows that the crystal corner has been truncated (white arrow). It is well known that resorption occurs preferentially at crystal corners because they are regions of high surface area (Donaldson 1985). The embayment marked with an unlabeled black arrow at the SE side of the 
figure is also likely the product of resorption. Although the overall olivine morphology resembles some skeletal morphologies presented by Welsch et al. (2014) (e.g., spongy olivine of their Fig. 1), one would expect to see herringbone-shaped $\mathrm{P}$ enrichments surrounded by a low-P region within the branches of the skeleton (i.e., on either side of the embayment) if it were formed by rapid growth. Instead, here we observe linear oscillations that are aligned on either side of the embayment and are truncated by the embayment (reaching the crystal rim at the embayment). We therefore believe that this deep incision within a crystal face is the product of resorption and not growth. In addition, it occurs at a crystal rim that already shows signs of resorption (crystal corner above). Given such an interpretation for this feature, by comparison, it is very likely that the low-P embayment in the P-rich oscillatory region (black arrow labeled "R") was also generated by an earlier resorption event. The P zoning in crystal 1957-A3, therefore, records two distinct resorption events at the rim. These resorption events must correspond to mafic magma recharge events that were hot and/or voluminous enough to modify crystal morphology. They are separated by a low-P region (marked "M"), which likely also formed during prolonged residence in a crystal mush. More recharge events may have occurred during the lifetime of this crystal. If either they were not hot and/or voluminous enough to resorb the crystal or they replaced low-P olivine by another generation of low-P olivine, they would not have been recorded. Crystal 1957-A3 is reversely zoned in Fo content, suggesting that it resided in cooler crystal mush and was reheated prior to eruption, in agreement with the observation of a late resorption event. This would imply full re-equilibration of $\mathrm{Fe}-\mathrm{Mg}$ in the skeletal, high-P region, from high Fo during its initial formation from recharge magma to low Fo during prolonged residence in the crystal mush.

Crystal 1957-B1 on the other hand is normally zoned in Fo, suggesting that it originated from the mafic recharge that interacted with cooler crystal mush prior to eruption. It's P zoning records only one recharge event with a high$\mathrm{P}$ skeletal core surrounding a melt inclusion (marked " $\mathrm{S}$ " in Fig. 3) that formed immediately after crystal nucleation. There is a concentric, P-rich region in the outer part of the crystal, which could be related to the high-P skeletal core (initial hollow hopper shape) or could have formed during a later event of rapid crystal growth. The high-P skeletal core is surrounded by a broad low-P region (marked "M"), which corresponds to slower crystal growth at lower degrees of undercooling, likely during the crystal's residence time in hybridized magma prior to eruption.

These two crystals show that combining elements which record changes in magma composition (i.e., magma recharge or mixing: $\mathrm{Fe}, \mathrm{Mg}, \pm \mathrm{Ca}, \mathrm{Mn}, \mathrm{Ni}$ ) with elements which record disequilibrium crystallization (i.e., rapid growth: $\mathrm{P}, \pm \mathrm{Al}, \mathrm{Ti}, \mathrm{Sc}, \mathrm{V}$ ) enables us to recover a much more complex history than could be inferred from Fo zoning alone. Plagioclase phenocrysts from the same samples were found to record three or more recharge events (Bouvet de Maisonneuve et al. 2013). A similar number of recharge events is recorded by crystal 1957-A3 (initial skeletal growth and two later resorption events) showing that the olivine archive can be broadly reconciled with the plagioclase archive when specific trace elements are examined in detail and in more than one dimension. We specifically focus on crystals 1957-A3 and B1, as trace element zoning in the core was not overlapping and therefore interfering with zoning at the rim.

\section{Timescales of processes from diffusion modeling}

The time elapsed between magma recharge and eruption is recorded by the zoning of Group 1 (Fo-like) elements at the rim, whereas the time elapsed between skeletal growth (i.e., just after olivine nucleation) and eruption is recorded by the zoning of Group 3 (hybrid) elements in the core. Both timescales can be quantified by kinetic modeling using a 2D diffusion model applicable to complex geometries. The lattice Boltzmann model described in the "Methods" section has been applied to coupled $\mathrm{Fe}-\mathrm{Mg}$ zoning near rims and Ti and Sc zoning in cores.

\section{Timescales between mixing with magma recharge and eruption}

Timescales between the interaction of mafic recharge with resident magma and eruption were constrained for nine olivine phenocrysts using $\mathrm{Mg} \mathrm{X}$-ray maps converted to quantitative Fo maps. Initial conditions consist of a crystal of the shape of the analyzed olivine with a uniform composition corresponding to the plateau measured in the core. Boundary conditions were maintained constant at the measured composition of the rim. Any discrepancies between the measured and the modeled concentrations were computed at each time step by the least square error in concentration integrated over the grain. The Fourier number, Fou, corresponding to the best fit (i.e., minimum least square error) was converted to a timescale using appropriate values for diffusivity. The diffusivities of $\mathrm{Fe}$ and $\mathrm{Mg}$ in olivine are anisotropic, strongly dependent on temperature and Fo content, and slightly dependent on pressure and oxygen fugacity (Table 3; Dohmen et al. 2007). Pressure and oxygen fugacity were considered to be $0.1 \mathrm{MPa}$ (atmospheric) and $5 \cdot 10^{-4} \mathrm{MPa}$ (close to the $\mathrm{Ni}-\mathrm{NiO}$ buffer at $1130{ }^{\circ} \mathrm{C}$ ). The temperature at which diffusion occurred is the most difficult parameter to constrain, as (1) it was probably not constant during diffusion (unlike in our model) and (2) 
Table 3 Olivine diffusivities of $\mathrm{Fe}-\mathrm{Mg}$, Ti, and $\mathrm{Sc}$ used in this study

\begin{tabular}{lll}
\hline & Equation & Refs. \\
\hline Fe-Mg & $D_{[001]}^{F e-M g}=6.17 \times 10^{-10}\left(\frac{f O_{2}}{10^{-7}}\right)^{1 / 6} 10^{3(0.9-F o)} \operatorname{Exp}\left[-\frac{201000+\left(P-10^{5}\right) 7 x 10^{-6}}{R T}\right]$ & Dohmen et al. (2007) \\
& $D_{[100]}^{F e-M g}=D_{[010]}^{F e-M g}=1 / 6 D_{[001]}^{F e-M g}$ & Cherniak and Liang (2014) $\times 1000$ \\
$\mathrm{Ti}$ & $D_{[001][010][100]}^{T i}=2.11 \times 10^{-14} \operatorname{Exp}\left[-\frac{195000( \pm 32000)}{R T}\right] \times 1000$ & This study* \\
\hline $\mathrm{Sc}$ & $D^{S c}=D^{T i}$ & \\
\hline
\end{tabular}

Temperatures are in $\mathrm{K}$ and the gas constant $\mathrm{R}$ is in $\mathrm{J} / \mathrm{mol} / \mathrm{K}$

* The diffusivity of Sc was considered to be the same as that of Ti

different crystals probably experienced different temperature histories depending on whether they were residing in evolved mush or carried by hotter recharge magma. Timescales are therefore reported as a function of temperature.

Hybrid magma temperatures calculated by olivine-melt equilibria at the crystal rim cluster around $1130-1150{ }^{\circ} \mathrm{C}$ in all three units (anhydrous estimates; Bouvet de Maisonneuve et al. 2012). If the average water content in the resident mush was $2 \mathrm{wt} \%$ (in agreement with melt inclusion data), pre-eruptive temperatures could have been closer to $1060-1080{ }^{\circ} \mathrm{C}$ rather than $1130-1150{ }^{\circ} \mathrm{C}$, after applying the correction of Médard and Grove (2008). If a single, characteristic temperature is to be used to reproduce diffusion under non-isothermal conditions, it should be close to the maximum temperature at which diffusion occurred as diffusion rates vary exponentially with temperature (Chakraborty and Ganguly 1991). We therefore considered diffusion to have occurred at the elevated temperatures of the hybrid magma rather than the cooler temperatures of the mush. Below we report timescale estimates for both anhydrous and hydrous $\left(2 \mathrm{wt} \% \mathrm{H}_{2} \mathrm{O}\right)$ conditions, as these represent two end-member scenarios that bound the range to be expected.

Two-dimensional diffusion modeling reproduces the Fo content of the maps within 1-1.5 mol\% (Fig. 7). Larger discrepancies occur at broken edges (e.g., 1957-A3, 1957-B6, LF3-A27), in crystals that show the effect of diffusion in the third dimension (e.g., UF3-D14 and E3), or where melt channels are connected to the exterior of the crystal (e.g., LF3-A27). These effects are small and do not substantially influence the final result, as zoning toward the rims in particular is well reproduced. Model results overlap for the three eruptions, with timescales of a few months to a few years for a temperature range between 1150 and $1060{ }^{\circ} \mathrm{C}$. In more detail, elapsed times between magma recharge and eruption seem to have been shorter prior to the 1957 summit eruption than prior to the early Fissural 3 eruption $(\mathrm{LF} 3, \sim 1850 \mathrm{AD})$ at a given temperature. If hydrous preeruptive temperatures of $1060-1080{ }^{\circ} \mathrm{C}$ are considered, magma recharge took place between 8 months and 3 years prior to the 1957 eruption, between 3 and 4.5 years prior to the UF3 eruption, and between 3 and 9 years prior to the LF3 eruption. With anhydrous pre-eruptive temperatures of $1130-1150{ }^{\circ} \mathrm{C}$, timescales would be reduced by approximately a factor of three.

Shorter time lags between the 1957 eruption and preceding recharge events are consistent with the long-term eruptive behavior of the main summit cone vent, from which a significant eruption occurred only 10 years prior to the very large 1957 event (Naranjo and Moreno 2005). Eruptions from the strikingly steep-sided main cone vent system, which is controlled by N-S-trending normal faults, are far more frequent and more voluminous on average than those from lower flank vents. The so-called Fissural 3 event (LF3-UF3 tephra) of Naranjo and Moreno (2005), to which we ascribe an age of $\sim 1850 \mathrm{AD}$, is a large lower flank vent eruption, but the two preceding phases of activity from this vent area are prehistoric and may have occurred up to several 1000 years B.P. We infer that the higher eruptive magma flux from the main summit vent system is associated with a much higher rate of background recharge, hence, a much higher probability that olivine crystals from large summit eruptions will record the higher pre-eruptive temperatures and shorter recharge-eruption lag times.

\section{Timescales between early crystal growth and eruption}

Timescales between olivine skeletal growth (i.e., immediately after nucleation) and eruption were constrained for two crystals (1957-A3 and B1) in which trace element zoning in the core was not overlapping with zoning at the rim (i.e., overprinted by subsequent recharge events). Initial conditions consist of a crystal with the shape of the analyzed olivine and a skeletal core of the shape of the high-P zone (Fig. 8). The skeletal core has initial enrichments in $\mathrm{Ti}$ and Sc related to the enrichments in $\mathrm{P}$ and dictated by the growth rate, partition coefficient, and diffusivity in the melt. The outer part of the crystal has no enrichments in Ti and Sc (i.e., value of 1) and defines the boundary condition. 
1957

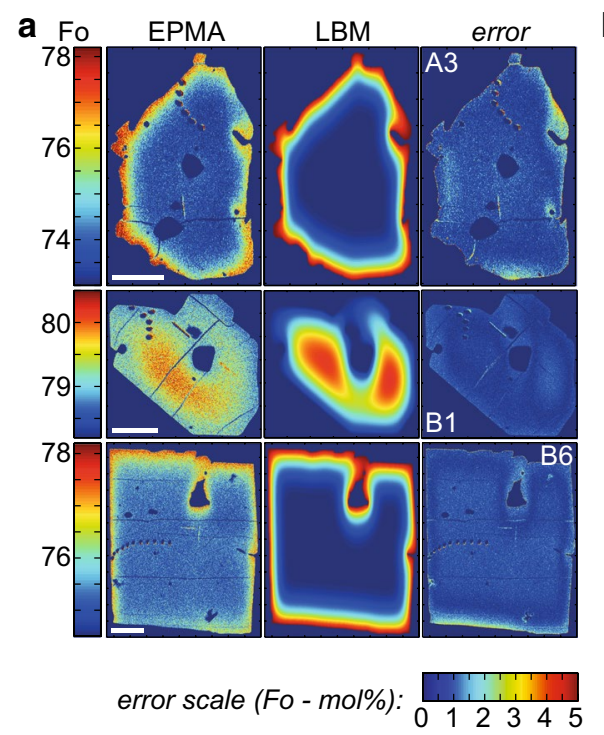

Upper F3

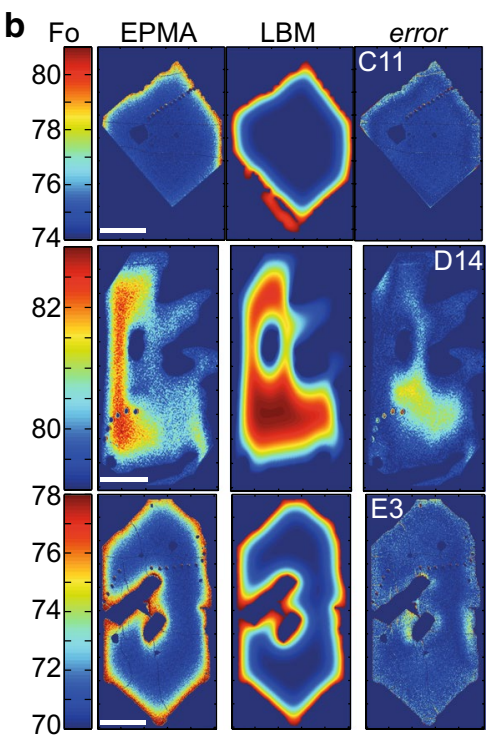

Lower F3

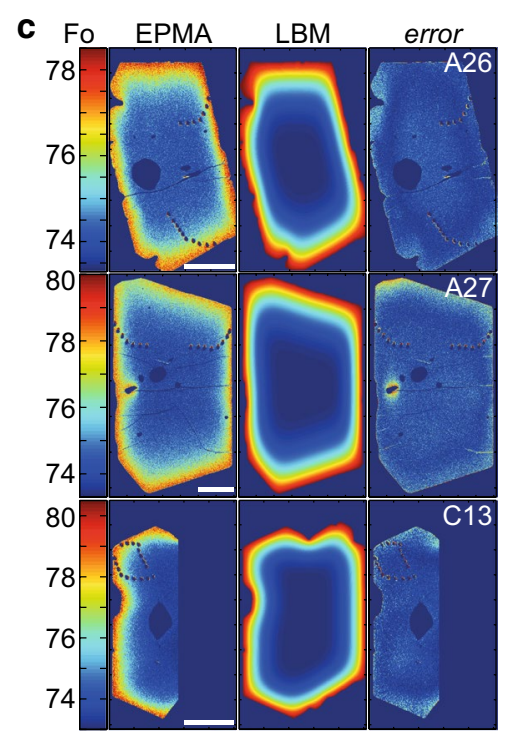

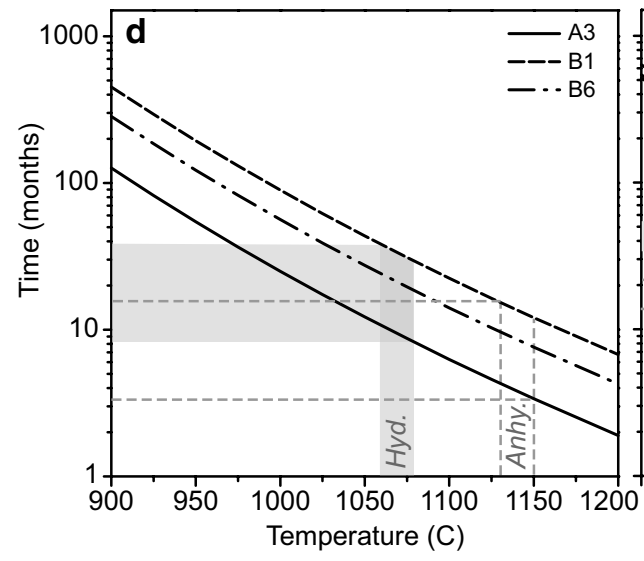

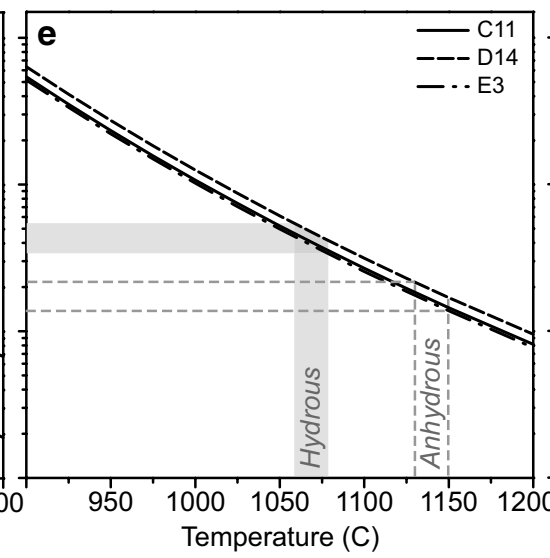

Fig. 7 2D lattice Boltzmann modeling (LBM) of the Fo zoning in the nine olivine crystals studied from the 1957 (a, d), UF3 (b, e), and LF3 (c, f) tephra deposits. (a-c) EPMA Mg X-ray maps converted to quantitative Fo maps, best fit Fo zoning map from LBM, and spatial distribution of the error (here shown as the difference in concentration between modeled and measured Fo) are shown for all crystals.
The color bar on the left of the maps shows the Fo content in the crystal, while the color bar at the base of (a) shows the magnitude of the error for all crystals. d-f Time elapsed between magma recharge and eruption as a function of temperature. The most likely range in temperatures and their associated timescales are shown with gray shaded areas (hydrous) and gray dashed lines (anhydrous estimates)
The P-rich oscillatory zoning near the crystal rim was not considered for modeling as (1) we believe that it belongs to a second rapid growth event that is not related to the skeletal core, and (2) this zone is not resolved well enough in the maps or the LA-ICP-MS data to be used as starting conditions for the modeling (i.e., exact shape and number of oscillations, $\mathrm{P}$ content of each oscillation). If this outer P-rich region is in fact related to the high-P skeleton, including it in the numerical model would improve the fit to the data but would not change the retrieved timescale. Measured LA-ICP-MS profiles were compared to a zone of similar dimensions and location on the modeled map: The location of the profile was estimated visually, and the $\mathrm{Ti}$ and $\mathrm{Sc}$ excesses along the profile were integrated over a $100-\mu \mathrm{m}$-wide zone reproducing the LA-ICP-MS acquisition method. Due to scatter in the LA-ICP-MS zoning profiles, the model's fit to the data was estimated visually and not computed at each time step. The Fourier number, Fou, corresponding to the best fit was converted to a timescale using appropriate values for the diffusivity.

The temperature-dependent diffusivity of Ti in olivine was studied by Cherniak and Liang (2014) under anhydrous conditions (at $1 \mathrm{~atm}$ with no addition of hydrous species). They observed no dependence on crystallographic orientation, Fo content, or oxygen fugacity and found very low diffusivities that are close to those of P (Spandler and O'Neill 2010) or Si in anhydrous olivine (Dohmen et al. 2002; Fei et al. 2012). $\mathrm{Ti}$ is in tetrahedral coordination and occupies the $\mathrm{Si}$ site in 
Fig. 8 2D lattice Boltzmann modeling of Ti and Sc zoning in the core of crystals 1957-A3 and B1. a-b Initial conditions, best fit profiles, and compositional maps for crystals A3 and B1, respectively. c Time elapsed between skeletal crystal growth and eruption as a function of temperature. The most likely range in temperatures and their associated timescales are shown with gray shaded areas. The temperature scale on the horizontal axis stretches from the coolest $\left(905^{\circ} \mathrm{C}\right.$, hydrous) to the warmest $\left(1175^{\circ} \mathrm{C}\right.$, anhydrous) temperatures measured for the three eruptions
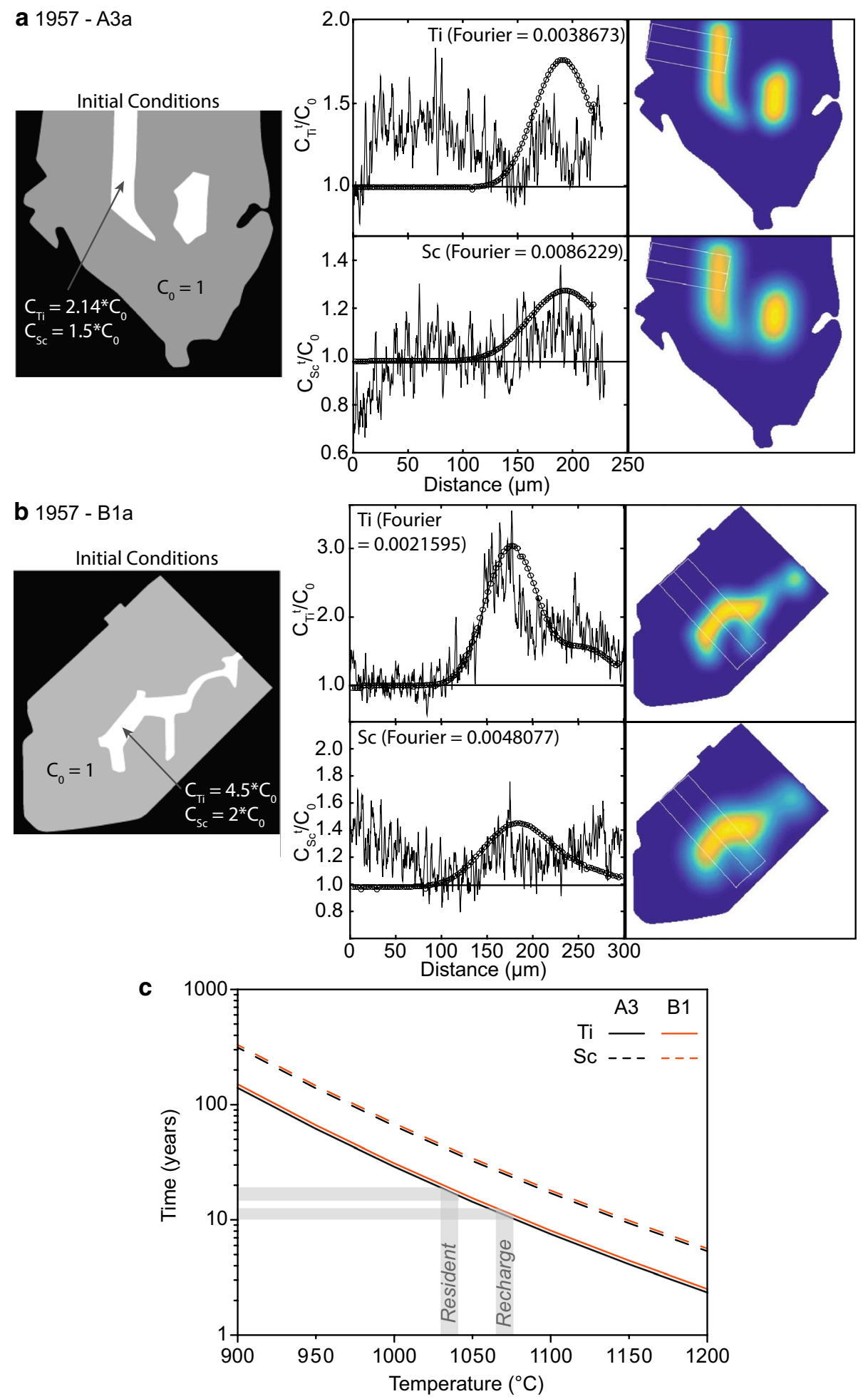

anhydrous olivine, but shifts to octahedral coordination and occupies an M1 site sharing an edge with a vacant Si site in hydrous olivine (Berry et al. 2007). Therefore, one would expect the diffusivity of $\mathrm{Ti}$ to be affected by that of $\mathrm{Si}$ in all cases. As the presence of only $10 \mathrm{ppm} \mathrm{H}_{2} \mathrm{O}$ in olivine will increase the diffusivity of Si by approximately three orders of magnitude (Costa and Chakraborty 2008), it seems likely that the diffusivity of Ti would increase by similar amounts in the presence of water. This would be the case for Llaima olivines, which host magmas contain $2 \mathrm{wt} \% \mathrm{H}_{2} \mathrm{O}$. Crystals 1957-A3 and $\mathrm{B} 1$ display a diffusion length for Ti that is shorter than that of $\mathrm{Fe}-\mathrm{Mg}$ at the rim and larger than that of $\mathrm{P}$ in the core 
(Fig. 6), in agreement with intermediate diffusivities that are greater than the experimentally derived anhydrous ones due to the stabilization of defects by $\mathrm{OH}$ groups (Berry et al. 2007; Costa and Chakraborty 2008). The diffusivity of Sc in olivine is not well constrained and was therefore taken to be the same as that of Ti.

Two-dimensional diffusion modeling cannot reproduce the measured profiles when initial enrichments dictated by the measured $\mathrm{P}$ enrichments are considered (i.e., Ti and Sc enrichments of 10.4 and 4.4 for crystal 1957-B1 and 4.8 and 3.2 for crystal 1957-A3). This could be due to the fact that $\mathrm{Ti}$ and Sc cannot be increased by such large amounts in the boundary layer melt due to structural considerations, or that diffusion in the third dimension has accounted for part of the decrease in concentration. 2D diffusion modeling can reproduce the $\mathrm{Ti}$ and $\mathrm{Sc}$ zoning profiles fairly well when lower enrichments of 4.5 and 2 for crystal 1957-B1 and 2.14 and 1.5 for crystal 1957-A3 are used (Fig. 8). Timescales for Sc are systematically larger, suggesting that its diffusivity is probably greater than that of Ti. Despite the fact that the timescales obtained here are very loosely constrained (scatter in the data-particularly Ti in crystal 1957-A3and uncertain diffusivities and initial concentrations), we believe that the method has a lot of potential to determine older timescales from crystal interiors. An improvement of the current knowledge on diffusivities of trace elements such as Ti, Sc, or V in olivine, and the analysis of such elements with higher precision (e.g., by secondary ion mass spectrometry) would yield much more reliable timescales.

The skeletal core of crystal 1957-B1 likely formed within the recharge magma, hence its Fo content of $81 \mathrm{~mol} \%$. Temperature estimates for the core of this crystal are at least $1070{ }^{\circ} \mathrm{C}$, considering hydrous conditions $\left(1.5 \mathrm{wt} \% \mathrm{H}_{2} \mathrm{O}\right.$ measured in the melt inclusion). At this temperature, the skeletal core would have formed 11 years prior to the 1957 eruption. It is difficult to estimate a single temperature for the diffusion of Ti and Sc out of the skeletal core of crystal 1957-A3, as this crystal has experienced a more prolonged and complex history of magma recharge, growth, and resorption. As for crystal 1957-B1, the skeletal core likely formed within the recharge magma, at temperatures around $1070{ }^{\circ} \mathrm{C}$ or higher. But the temperature then fluctuated and decreased through time. Temperature estimates for the core (Fo $=73.5 \mathrm{~mol} \%$ ) of crystal 1957-A 3 are around $1035{ }^{\circ} \mathrm{C}$, considering hydrous conditions ( $2 \mathrm{wt} \% \mathrm{H}_{2} \mathrm{O}$ measured in the melt inclusion). At temperatures intermediate between 1035 and $1070{ }^{\circ} \mathrm{C}$, this skeletal core would have formed $\sim 11-19$ years prior to the 1957 eruption.

\section{Olivine zoning, magmatic processes, and timescales at Llaima}

In summary, individual olivine phenocrysts appeared to record only one magma recharge event if only $\mathrm{Fo}, \mathrm{Mn}, \mathrm{Ca}$, and $\mathrm{Ni}$ zoning are considered, but may in fact have experienced a complex history, including multiple recharge events given their $\mathrm{P}, \mathrm{Sc}$, and Ti zoning. This complex history involving multiple events of crystal growth, dissolution, and re-equilibration is similar to what is seen in the textures and An contents of plagioclase phenocrysts. It suggests that these minerals are coeval and have similar residence times in the shallow conduit/reservoir system at Llaima. In this view, the plagioclase and olivine records are reconciled. The initial dichotomy of simple versus complex magmatic processes experienced by both minerals no longer holds true.

Fo zoning at the olivine rims suggests that mixing with a recharge magma occurs on the order of a few months to a few years prior to eruption, for the small number of crystals we have examined. Many olivine crystals from some historic lava eruptions record large and abrupt reversely zoned profiles, and some of these extend to the grain edge without a late normally zoned outer rim. Rim compositions converge on similar values in some lava thin sections, but in others a wide range of rim compositions and a great diversity of zoning patterns are documented (see Fig. 5 of Bouvet de Maisonneuve et al. 2013). These observations can only be explained if crystals that had resided in crystal mush came into contact with recharge magmas shortly before eruption.

Crystal residence times in the shallow reservoirs are on the order of a few years to decades, as estimated by Ti and Sc zoning in their cores. These timescales suggest that the frequency of recharge events is on the order of a decade or more. This is less than the volcano's overall frequency of eruption 5.6 years (Dzierma and Wehrmann 2010), but individual olivines in the subvolcanic conduit/reservoir system probably record only a small fraction of the total number of recharge events, which must vary in magnitude and are probably dispersed among a large number of dikes and sills. Each eruption is probably associated with one or a swarm of variable-volume magma recharge events, in agreement with the large number of reversely zoned olivine phenocrysts in the tephra and lavas (Bouvet de Maisonneuve et al. 2012, 2013). Eruption volumes are likely to be crudely proportional to the aggregate volume of recharge magma in such swarms, and large eruptions may reflect the arrival of an anomalously large batch of recharge magma that may serve as the proximal eruption-triggering event. Closer links to pre-eruptive recharge and the nature of eruption-triggering processes require integration of petrologic data and model results derived from erupted samples with pre-eruptive and syn-eruptive geophysical data.

The 2008-2009 eruption is the only Llaima event for which there is precursory geophysical monitoring data. The precursory seismic activity that characterized the mid-2007 period had diminished to a lower level by late 2007, and 


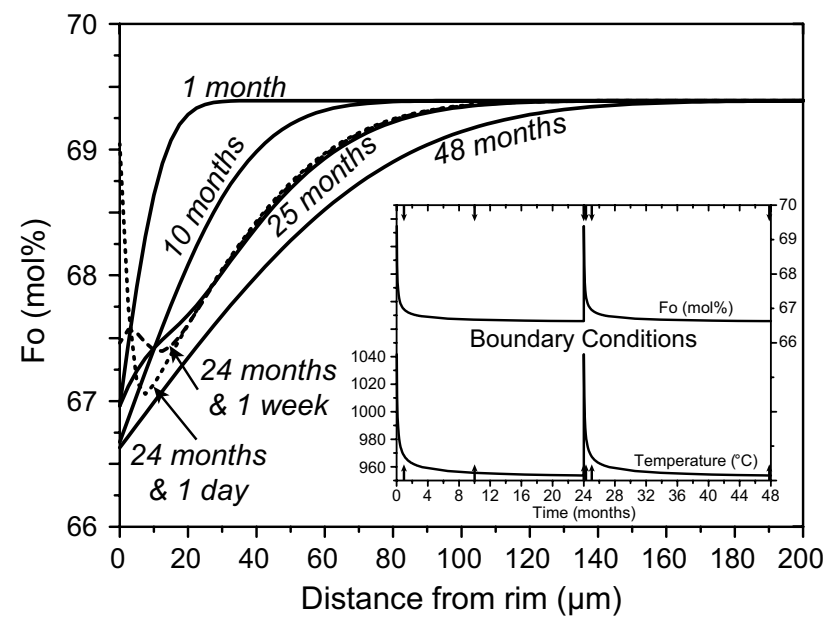

Fig. 9 One-dimensional diffusion modeling in olivine, parallel to the $c$-axis and with changing temperature and boundary conditions through time (shown in the inset). The arrival of a recharge magma, simulated as an increases in both temperature and Fo content at the boundary, will be recorded by the crystal but is lost in a few weeks due to diffusion and the short-lived nature of this event

there was no seismic swarm immediately before the onset of the main eruption on January 1, 2008 (Hugo Moreno, personal communication 2010). The methods developed in this study should be tested and refined by characterization and modeling of crystals acquired by real-time sampling of a subsequent eruption of Llaima that will benefit from ongoing, post-2008 geophysical monitoring and comprehensive observations during the eruption.

Unlike phosphorus, which records multiple recharge events, $\mathrm{Fo}, \mathrm{Mn}, \mathrm{Ni}$, and $\mathrm{Ca}$ seem to record no more than one recharge event. This is surprising as $\mathrm{Fe}$ and $\mathrm{Mg}$ diffusion in olivine is sufficiently slow to record processes operating on the timescales of decades (Costa and Chakraborty 2004; Morgan et al. 2004; Costa and Dungan 2005; Morgan et al. 2006). The absence of information on early magma recharge events could be due to the fact that the signal from earlier recharge events was erased by diffusion and/ or interferences from preexisting zoning, and is no longer resolvable analytically (Fig. 9). This is possible if variations in concentration at the boundary are of small amplitude (i.e., limited compositional contrast between the residing and incoming magmas) and last for a limited amount of time. The durations of interactions between the resident and replenishing magmas are presumed to be much shorter (weeks-months) than typical olivine residence times in crystal mushes during quiescence (years). Such offsets in the timescales of resetting compositions versus diffusive relaxation allow for any minor amplitude "spikes and troughs" in zoning profiles to be rapidly diminished. The unexpectedly long timescales obtained by kinetic modeling of Fo zoning could suggest that the modeled zoning profiles were affected by multiple overlapping recharge events of short duration, and are not exclusively the product of the latest event. If this is the case, normally zoned olivines that originated from the latest recharge magma are the most faithful recorders of the time elapsed between the latest recharge event and eruption.

\section{Conclusions}

The acquisition of a number of compositional traverses of elements with different concentrations and geochemical properties in multiple olivine crystals provides us with a framework for interpreting the processes that operate prior to historic eruptions at Llaima. Three groups of elements can be defined: (Group 1) Ni, Mn, $\pm \mathrm{Ca}$, and $\pm \mathrm{Y}$ follow Fo content with concentric zoning at the rims but no zoning in the cores; (Group 2) P and $\pm \mathrm{Al}$ display skeletal enrichments in the core and occasionally concentric and moderate enrichments near rims; and (Group 3) $\mathrm{Ti}, \mathrm{Sc}, \mathrm{V}$, and $\pm \mathrm{Cr}$ follow both Fo content and $\mathrm{P}$ with skeletal enrichments in the core and concentric zoning at the rims. Groups 1 and $\mathbf{3}$ record changes in magma composition, typically by mixing between a mafic recharge and the more evolved resident crystal mush. Elements in Groups $\mathbf{2}$ and $\mathbf{3}$ record kinetic disequilibrium partitioning during rapid crystal growth, for example immediately after crystal nucleation.

Trace element contents of olivines support the model of Llaima magmas being produced by a balance between (1) injections of mafic crystal-poor magma into shallow magma reservoirs, (2) intense crystallization following decompression and degassing of the injected magma, and (3) eruption of crystal-rich basaltic-andesitic magma in response to subsequent recharge events (Fig. 1; Bouvet de Maisonneuve et al. 2012, 2013). The recharge and resident magmas are broadly cogenetic (not derived from a single parent magma batch), as trace element variations can be explained by olivine crystallization essentially and are similar for the crystals of three different eruptions (1957, 1850 Upper Fissural 3, and 1850 Lower Fissural 3).

Individual olivine phenocrysts may experience up to three or more recharge events during their life spans in the shallow reservoirs of Volcán Llaima, as recorded by $\mathrm{P}( \pm \mathrm{Ti}, \mathrm{Sc}, \mathrm{V}, \mathrm{Cr}$, and $\mathrm{Al})$. This is comparable to the plagioclase record (Bouvet de Maisonneuve et al. 2013). Fo contents and zoning profiles for most other elements seem to preserve only one recharge event. This could be due to the fact that the zoning profiles induced by recharge events have overlapping records and are diffusively erased during prolonged periods of quiescence. The measured zoning in Fo, Mn, Ca, and Ni could therefore be the result of multiple overprinted signatures of recharge events. The most reliable estimates for the time elapsed between the latest magma 
recharge event and eruption are provided by normally zoned olivines that originated from the recharge magma and record only one recharge event in their P zoning. These timescales are on the order of a few months to a couple of years. Crystal residence times in shallow Llaima reservoirs are on the order of a few years to decades, as estimated by $\mathrm{Ti}$ and Sc zoning in the cores of two olivines.

Olivines have the potential to accurately record magmatic events if zoning profiles from both major and trace elements with different geochemical properties are studied in combination. The use of both element maps and highresolution profiles in combination with $2 \mathrm{D}$ diffusion modeling leads to improved accuracy of estimated timescales over a 1D approach and also provides a way to assess the importance of 3D effects, which cannot be constrained from polished section surfaces. The apparently simple zoning patterns in Fo, Mn, Ca, and Ni must be interpreted with caution, as they will not reveal the full complexities of a phenocryst's history.

Acknowledgments This project was supported by the Swiss NSF Grant \#20_125019 to M.A. Dungan, the Swiss NSF fellowship PBGEP2-139851 to C. Bouvet de Maisonneuve, and the National Research Foundation Singapore and the Singapore Ministry of Education under the Research Centres of Excellence initiative. C. Huber acknowledges support from NSF EAR-1454821, and F. Costa acknowledges support from MOE2014-T2-2-041. C. Bouvet de Maisonneuve thanks Hugh O'Neill and Carl Spandler for their precious help during acquisition and processing of trace element LA-ICP-MS data and access to their laboratory.

Open Access This article is distributed under the terms of the Creative Commons Attribution 4.0 International License (http://creativecommons.org/licenses/by/4.0/), which permits unrestricted use, distribution, and reproduction in any medium, provided you give appropriate credit to the original author(s) and the source, provide a link to the Creative Commons license, and indicate if changes were made.

\section{References}

Albarède F, Bottinga Y (1972) Kinetic disequilibrium in trace element partitioning between phenocrysts and host lava. Geochim Cosmochim Acta 36(2):141-156

Baker DR (2008) The fidelity of melt inclusions as records of melt composition. Contrib Mineral Petrol 156(3):377-395

Beattie P (1994) Systematics and energetics of trace-element partitioning between olivine and silicate melts: implications for the nature of mineral melt partitioning. Chem Geol 117(1-4):57-71

Berry AJ, Walker AM, Hermann J, O’Neill HSC, Foran GJ, Gale JD (2007) Titanium substitution mechanisms in forsterite. Chem Geol 242(1):176-186

Blundy J, Cashman K (2005) Rapid decompression-driven crystallization recorded by melt inclusions from Mount St. Helens volcano. Geology 33(10):793-796. doi:10.1130/g21668.1

Blundy J, Cashman K (2008) Petrologic reconstruction of magmatic system variables and processes. Miner Incl Volcan Process 69:179-239. doi:10.2138/rmg.2008.69.6
Bouvet de Maisonneuve C, Dungan MA, Bachmann O, Burgisser A (2012) Insights into shallow magma storage and crystallization at Volcán Llaima (Andean Southern Volcanic Zone, Chile). J Volcanol Geotherm Res 211:76-91. doi:10.1016/j. jvolgeores.2011.09.010

Bouvet de Maisonneuve C, Dungan MA, Bachmann O, Burgisser A (2013) Petrological insights into shifts in eruptive styles at Volcán Llaima (Chile). J Petrol 54(2):393-420. doi:10.1093/ petrology/egs073

Brunet F, Chazot G (2001) Partitioning of phosphorus between olivine, clinopyroxene and silicate glass in a spinel lherzolite xenolith from Yemen. Chem Geol 176(1-4):51-72

Chakraborty S (2010) Diffusion coefficients in olivine, wadsleyite and ringwoodite. Diffus Miner Melts 72:603-639. doi:10.2138/ rmg.2010.72.13

Chakraborty S, Ganguly J (1991) Compositional zoning and cation diffusion in garnets. In: Ganguly J (ed) Diffusion, atomic ordering, and mass transport, vol advances physical geochemistry. Springer, New York, pp 120-175

Cherniak DJ, Liang Y (2014) Titanium diffusion in olivine. Geochim Cosmochim Acta 147:43-57

Costa F, Chakraborty S (2004) Time scales of igneous differentiation obtained from diffusion modeling of compositional zoning in olivine. Geochim Cosmochim Acta 68(11):A642-A642

Costa F, Chakraborty S (2008) The effect of water on Si and O diffusion rates in olivine and implications for transport properties and processes in the upper mantle. Phys Earth Planet Inter 166(1):11-29

Costa F, Dungan M (2005) Short time scales of magmatic assimilation from diffusion modeling of multiple elements in olivine. Geology 33(10):837-840. doi:10.1130/g21675.1

Costa F, Morgan D (2010) Time constraints from chemical equilibration in magmatic crystals. In: Dosseto A, Turner SP, Van Orman JA (eds) Timescales of magmatic processes: from core to atmosphere. Wiley, Oxford, pp 125-159

Costa F, Dohmen R, Chakraborty S (2008) Time scales of magmatic processes from modeling the zoning patterns of crystals. Diffus Miner Melts 69:545-594. doi:10.2138/rmg.2008.69.14

Costa F, Andreastuti S, Bouvet de Maisonneuve C, Pallister JS (2013) Petrological insights into the storage conditions, and magmatic processes that yielded the centennial 2010 Merapi explosive eruption. J Volcanol Geotherm Res 261:209-235. doi:10.1016/j. jvolgeores.2012.12.025

Dohmen R, Chakraborty S, Becker HW (2002) Si and O diffusion in olivine and implications for characterizing plastic flow in the mantle. Geophys Res Lett 29(21):26-21-26-24

Dohmen R, Becker H-W, Chakraborty S (2007) Fe-Mg diffusion in olivine I: experimental determination between 700 and 1,200 $\mathrm{C}$ as a function of composition, crystal orientation and oxygen fugacity. Phys Chem Miner 34(6):389-407

Donaldson CH (1985) The rates of dissolution of olivine, plagioclase, and quartz in a basalt melt. Mineral Mag 49(354):683-693

Dostal J, Dupuy C, Carron JP, Dekerneizon ML, Maury RC (1983) Partition coefficients of trace elements: application to volcanic rocks of St-Vincent, West-Indies. Geochim Cosmochim Acta 47(3):525-533

Duke JM (1976) Distribution of period 4 transition elements among olivine, calcic clinopyroxene and mafic silicate liquid: experimental results. J Petrol 17(4):499-521

Dunn T (1987) Partitioning of Hf, Lu, Ti, and Mn between olivine, clinopyroxene and basaltic liquid. Contrib Mineral Petrol 96(4):476-484

Dzierma Y, Wehrmann H (2010) Eruption time series statistically examined: probabilities of future eruptions at Villarrica and Llaima Volcanoes, Southern Volcanic Zone, Chile. 
J Volcanol Geotherm Res 193(1-2):82-92. doi:10.1016/j. jvolgeores.2010.03.009

Eggins S, De Deckker P, Marshall J (2003) Mg/Ca variation in planktonic foraminifera tests: implications for reconstructing palaeoseawater temperature and habitat migration. Earth Planet Sci Lett 212(3-4):291-306. doi:10.1016/S0012-821x(03)00283-8

Fei H, Hegoda C, Yamazaki D, Wiedenbeck M, Yurimoto H, Shcheka S, Katsura T (2012) High silicon self-diffusion coefficient in dry forsterite. Earth Planet Sci Lett 345:95-103

Gaetani GA, Grove TL (1997) Partitioning of moderately siderophile elements among olivine, silicate melt, and sulfide melt: constraints on core formation in the Earth and Mars. Geochim Cosmochim Acta 61(9):1829-1846

Grove TL, Baker MB, Kinzler RJ (1984) Coupled CaAl-NaSi diffusion in plagioclase feldspar: experiments and applications to cooling rate speedometry. Geochim Cosmochim Acta 48(10):2113-2121

Huber C, Chopard B, Manga M (2010) A lattice Boltzmann model for coupled diffusion. J Comput Phys 229(20):7956-7976. doi:10.1016/j.jcp.2010.07.002

Huber C, Cassata WS, Renne PR (2011a) A lattice Boltzmann model for noble gas diffusion in solids: the importance of domain shape and diffusive anisotropy and implications for thermochronometry. Geochim Cosmochim Acta 75(8):2170-2186

Huber C, Dufek J, Chopard B (2011b) A simple algorithm to enforce Dirichlet boundary conditions in complex geometries. Int J Mod Phys C 22(10):1093-1105

Ito M, Ganguly J (2006) Diffusion kinetics of $\mathrm{Cr}$ in olivine and Mn-53-Cr-53 thermochronology of early solar system objects. Geochim Cosmochim Acta 70(3):799-809. doi:10.1016/j. gca.2005.09.020

Jochum KP, Nohl U, Herwig K, Lammel E, Stoll B, Hofmann AW (2005) GeoReM: a new geochemical database for reference materials and isotopic standards. Geostand Geoanal Res 29(3):333-338

Kazahaya K, Shinohara H, Saito G (1994) Excessive degassing of Izu-Oshima volcano: magma convection in a conduit. Bull Volcanol 56(3):207-216

Larsen ES, Irving J, Gonyer FA, Larsen ESI (1938) Petrologic results of a study of the minerals from the Tertiary volcanic rocks of the San Juan region, Colorado. Am Mineral 23(7):227-257

Longerich HP, Jackson SE, Gunther D (1996) Laser ablation inductively coupled plasma mass spectrometric transient signal data acquisition and analyte concentration calculation. J Anal At Spectrom 11(9):899-904

Lowry RK, Henderson P, Nolan J (1982) Tracer diffusion of some alkali, alkaline-earth and transition element ions in a basaltic and an andesitic melt, and the implications concerning melt structure. Contrib Mineral Petrol 80(3):254-261

Médard E, Grove TL (2008) The effect of $\mathrm{H} 2 \mathrm{O}$ on the olivine liquidus of basaltic melts: experiments and thermodynamic models. Contrib Mineral Petrol 155(4):417-432. doi:10.1007/ s00410-007-0250-4

Milman-Barris MS, Beckett JR, Baker MB, Hofmann AE, Morgan Z, Crowley MR, Vielzeuf D, Stolper E (2008) Zoning of phosphorus in igneous olivine. Contrib Mineral Petrol 155(6):739-765. doi:10.1007/s00410-007-0268-7

Morgan DJ, Blake S, Rogers NW, DeVivo B, Rolandi G, Macdonald R, Hawkesworth CJ (2004) Time scales of crystal residence and magma chamber volume from modelling of diffusion profiles in phenocrysts: Vesuvius 1944. Earth Planet Sci Lett 222(34):933-946. doi:10.1016/j.eps1.2004.03.030

Morgan DJ, Blake S, Rogers NW, De Vivo B, Rolandi G, Davidson JP (2006) Magma chamber recharge at Vesuvius in the century prior to the eruption of AD 79. Geology 34(10):845-848. doi:10.1130/ G22604.1
Naranjo JA, Moreno H (2005) Geología del volcán Llaima, Región de la Araucanía. In: Carta Geológica de Chile, Serie Geología Básica, vol. Servicio Nacional de Geología y Minería, Santiago

Nielsen RL, Gallahan WE, Newberger F (1992) Experimentally determined mineral-melt partition-coefficients for Sc, Y and Ree for olivine, ortho-pyroxene, pigeonite, magnetite and ilmenite. Contrib Mineral Petrol 110(4):488-499

Nikogosian IK, Sobolev AV (1997) Ion-microprobe analysis of melt inclusions in olivine: experience in estimating the melt-olivine partitioning coefficients of elements. Geokhimiya 2:149-157

Prior DJ, Boyle AP, Brenker F, Cheadle MC, Day A, Lopez G, Peruzzo L, Potts GJ, Reddy S, Spiess R (1999) The application of electron backscatter diffraction and orientation contrast imaging in the SEM to textural problems in rocks. Am Mineral 84:1741-1759

Reubi O, Bourdon B, Dungan MA, Koornneef JM, Sellés D, Langmuir CH, Aciego S (2011) Assimilation of the plutonic roots of the Andean arc controls variations in U-series disequilibria at Volcán Llaima, Chile. Earth Planet Sci Lett 303(1-2):37-47. doi:10.1016/j.epsl.2010.12.018

Ruth DCS (2014) Physical and geochemical systematics of the 2008 violent strombolian eruption of Llaima Volcano, Chile. State University of New York, Buffalo

Schindlbeck JC, Freundt A, Kutterolf S (2014) Major changes in the post-glacial evolution of magmatic compositions and pre-eruptive conditions of Llaima Volcano, Andean Southern Volcanic Zone, Chile. Bull Volcanol 76(6):1-22

Shea T, Lynn KJ, Garcia MO (2015) Cracking the olivine zoning code: distinguishing between crystal growth and diffusion. Geology 43(10):935-938

Shinohara H (2008) Excess degassing from volcanoes and its role on eruptive and intrusive activity. Rev Geophys. doi:10.1029/200 $7 \mathrm{rg} 000244$

Spandler C, O'Neill HS (2010) Diffusion and partition coefficients of minor and trace elements in San Carlos olivine at 1300 degrees $\mathrm{C}$ with some geochemical implications. Contrib Mineral Petrol 159(6):791-818. doi:10.1007/s00410-009-0456-8

Spandler C, O’Neill HSC, Kamenetsky VS (2007) Survival times of anomalous melt inclusions from element diffusion in olivine and chromite. Nature 447(7142):303-306

Streck MJ (2008) Mineral Textures and Zoning as Evidence for Open System Processes. Miner Incl Volcan Process 69:595-622. doi:10.2139/rmg.2008.69.15

Tomkeieff SI (1939) Zoned olivines and their petrogenetic significance. Mineral Mag 25:229-251

Villemant B (1988) Trace-element evolution in the phlegrean fields (Central-Italy): fractional crystallization and selective enrichment. Contrib Mineral Petrol 98(2):169-183

Watson EB (1977) Partitioning of manganese between forsterite and silicate liquid. Geochim Cosmochim Acta 41(9):1363-1374

Watson EB, Cherniak DJ, Holycross ME (2015) Diffusion of phosphorus in olivine and molten basalt. Am Mineral 100(10):2053-2065

Welsch B, Faure F, Famin V, Baronnet A, Bachèlery P (2013) Dendritic crystallization: a single process for all the textures of olivine in basalts? J Petrol 54(3):539-574

Welsch B, Hammer JE, Hellebrand E (2014) Phosphorus zoning reveals dendritic architecture of olivine. Geology 42(10):867-870

Wolf-Gladrow DA (2000) Lattice-gas cellular automata and lattice boltzmann models: an introduction. Springer, Berlin

Zhang YX, Ni HW, Chen Y (2010) Diffusion data in silicate melts. Diffus Miner Melts 72:311-408. doi:10.2138/rmg.2010.72.8 